\title{
III.
}

\section{Zur Terminologie der römischen Rechtsquellen in der Lehre von der Unwirksamkeit der juristischen Tatsachen.}

\author{
Von \\ Herrn Dr. Hellmann \\ in München. \\ (SchluB.)
}

\section{IV.}

Aus der bisherigen Untersuchung des Sprachgebrauchs ergibt sich die Berechtigung, einen gewissen Bestand von Redewendungen als technisch zur Bezeichnung der Unwirksamkeit von Tatsachen, die an sich zu den juristischen gehören, in Anspruch zu nehmen.

Diese Wendungen sind:

Non consistere, corrumpi, infirmari, vitiari, effectum non habere, inefficax esse, non esse, locum non habere, frustra esse (facere), impediri, irritum esse, non iure, non recte fieri (facere), non licere, non posse, nullum esse, pro nihilo esse, nullius momenti esse, ratum non haberi, servari non oportere, non videri factum, pro eo haberi ac si factum non esset.

Alle diese Wendungen sind verbal. Einen substantivischen Ausdruck für Wirkungslosigkeit kann man allerdings in den Quellen nicht nachweisen, ebensowenig wie für das Gegenteil. Das hindert jedoch natürlich nicht die Annahme eines technischen Sprachgebrauchs eben der verbalen Wendungen. 
Denn als technisch dürfen wir einen Ausdruck wohl bezeichnen, wenn ihn die Lehre einer Kunst oder Wissenschaft zur Kennzeichnung eines ihr angehörigen Begriffes ständig verwendet.

Auffallen könnte vielleicht einerseits die Mannigfaltigkeit der Mittel, deren sich die römische Rechtssprache zur Bezeichnung des nämlichen Begriffes bedient, anderseits die Tatsache, daß keineswegs alle zur Verfügung stehenden Ausdrücke sich in Verbindung mit allen juristischen Tatsachen nachweisen lassen.

Allein die Mannigfaltigkeit der Bezeichnungen kann gegen die Eigenschaft der einzelnen als eines technischen Ausdrucks wohl überhaupt nicht angeführt werden; sie zeigt nur den Reichtum der Sprache an; der andere Umstand aber darf wohl teils auf Zufall zurückgeführt werden, teils darauf, $\mathrm{da} \beta$ einzelne Wendungen besonders im Schwange gewesen zu sein scheinen, endlich auch darauf, daß einzelne juristische Tatsachen wegen ihrer praktischen Bedeutung eine öftere Erwähnung in den Quellen finden, so daß die Gelegenheit, ihre Unwirksamkeit mit den verschiedenen zu Gebote stehenden Wendungen zu bezeichnen, eine reichlichere gewesen ist. Wie berechtigt diese letztere Vermutung ist, wird klar, wenn man erwägt, daß z. B. für donatio, donare alle technischen Bezeichnungen der Unwirksamkeit mit Ausnahme von corrumpere (vitiari, infirmari), inane esse, non videri factum, pro eo habendum ac si factum non esset, non esse vorkommen, für emptio, emere alle mit Ausnahme von corrumpere, inutile esse, inane esse, non videri factum, ratum non haberi, für venditio alle mit Ausnahme von frustra fieri, inutile, inane, irritum esse, non esse, für stipulatio alle mit Ausnahme von irritum esse, non consistere, non esse, inefficax esse, pro eo habendum ac si factum non esset, recte non fieri, für legatum alle mit Ausnahme von inane esse, nihil agi, non esse, non videri factum, während hinwieder für pollicitatio sich ganz allein nullas vires habere findet, für emancipatio nur non valere, für aestimatio nur non valere und nullum esse.

Einzelne Wendungen sind fast ausschließlich für eine bestimmte Tatsache gebräuchlich, wie z. B. servari non opor- 
tere für pactum, wieder andere werden nur auf Handlungen unter vivos angewendet, wie z. B. nihil agi.

Angesichts der Feststellung des technischen Sprachgebrauchs der Quellen muß man sich stets vor Augen halten, was oben (S. 5) ausgesprochen wurde, daß nämlich ein Urteil des Rechts über die Wirkungsfähigkeit eines Tatbestandes, welchem eine solche nirgends beigelegt worden ist, weil gänzlich überflüssig, nicht erwartet werden darf. Ebensowenig aber darf erwartet werden, daß von einem Tatbestande, der nicht vorhanden ist, diese $\mathrm{Nichtexistenz}$ besonders festgestellt werde, wo nicht $\mathrm{Zweifel}$ über die Existenz begründet sind, noch weniger aber, daß die Nichtexistenz festgestellt werde, um auszudrücken, daß der vorhandene Tatbestand nicht die Wirkung eines nicht vorhandenen Tatbestandes habe.

Diese überflüssig scheinende Bemerkung ist gerechtfertigt mit Rücksicht darauf, daß unter den technischen Bezeichnungen der Wirkungsunfähigkeit eines Tatbestandes eine große Rolle spielen: nullum esse und non esse und sprachlich nichts im Wege steht, diese Wendungen als die Konstatierung des Nichtdaseins aufzufassen.

Leonhard ${ }^{1}$ ) glaubt die Beobachtung gemacht zu haben, „daß im Pandektenlatein das Wort nullus als Subjekt oder als Adjektivum verwendet in der Regel soviel bedeutet wie "niemand", "kein" oder "nicht vorhanden", daß es dagegen da, wo es als Prädikat erscheint, gewöhnlich den Begriff "nichtig" zum Ausdruck bringt.

Allerdings ist nicht zu leugnen, daß nullus auch in den Quellen mehrfach lediglich zur Bezeichnung des Nichtdaseins von Tatsachen verwendet wird, und insofern treffen die von Leonhard (a. a. O. S. 388 1 u. 2) angeführten Belege zu. Allein aus denselben ist zugleich ersichtlich, daß sie sich mit der Aufgabe, ein Urteil über die Wirkungsfähigkeit eines Tatbestandes zu fällen, gar nicht befassen.

Vgl. noch z. B. 1. 5 D. 28. 3: 'quia nullus est.'

l. $104 \$ 1$ D. 30 : 'si . . tabulae nullae fuerunt.'

1) Leonhard, Der Irrtum S. 297 u. 388 u. Allg. Teil des BGB. S. 430 . 
1. 26 D. 39. 5: 'nulla donatio intelligitur.'

1. 7 C. 3. 1: "inter servum et liberum consistere iudicium nullum possit.'

1. 11 D. 28. 3: 'quia sequens (testamentum) nullum est.'

1. 23 C. 4.65 : 'nullum habeat consensum.'

Wo immer aber dies der Fall ist, da bedeutet nullus nicht das Nichtvorhandensein eines Tatbestandes, sondern das Nichtvorhandensein seiner normalen Rechtswirkungen, setzt also die Existenz des Tatbestandes voraus. Ein Unterschied der Bedeutung, je nach dem adjektivischen oder prädikativischen Gebrauch des Wortes ist für jene Fälle nicht nachzuweisen; im Gegenteil finden sich zahlreiche Stellen, in welchen nullus bei adjektivischer Verwendung die Unwirksamkeit eines bestimmten Tatbestandes ausdrückt:

1. $51 \S 2$ D. 29.2. African 1. 4 quaest.: $\mathrm{Si}$ quis ita dixerit: 'Si solvendo hereditas est, adeo hereditatem' nulla aditio est.

Daß der Tatbestand der hereditatis aditio hier vorliegt, daß er in der Erklärung liegt adeo hereditatem, darf angesichts der 1.77 D. 50.17 nicht bezweifelt werden. Denn diese letztere spricht ausdrücklich von in totum vitiari des actus legitimus durch adiectio eines dies oder einer conditio. Es ist daher der Zusatz, welcher die Wirkungsfähigkeit dem Tatbestande 'aditio' entzieht, die ihm sonst, ohne den Zusatz, zukäme.

1. $41 \S 3$ D. 28.6. Papin. 1.6 respons. Quod si heredem filium pater rogaverit, si impubes diem suum obierit, Titio hereditatem suam restituere, legitimum heredem filii salva Falcidia cogendum patris hereditatem ut ab impubere fideicommisso post mortem eius dato restituere placuit, nec aliud servandum, cum substitutionis condicio puberem aetatem verbis precariis egreditur. quae ita locum habebunt, si patris testamentum iure valuit: alioquin si non valuit ea scriptura, quam testamentum esse voluit, codicillos non faciet, nisi hoc expressum est. nec fideicommisso propriae facultates filii tenebuntur, et ideo, si pater filium exheredaverit et ei nihil reliquerit, nullum fideicommissum erit. 
Diese Entscheidung: nullum fideicommissum erit gibt der Jurist von dem Tatbestande: Si heredem filium pater rogaverit, ... Titio hereditatem ... restituere, d. h. von einem Tatbestande, der die äußere Erscheinung des fideicommissum ausmacht; es ist daher klar, daß die Entscheidung nicht besagen kann, dieser Tatbestand sei nicht vorhanden, sondern nur: er habe nicht seine normale Wirkungsfähigkeit. ${ }^{1}$ )

1. 11 D. 7.5. Ulpian 1.18 ad Sab. Si lanae alicui legatus sit usus fructus vel odorum vel aromatum, nullus videtur ususfructus in istis iure constitutus. ....

Daß nullus hier als Adjektivum zu ususfructus gehört, trotzdem es durch videtur davon getrennt wird, steht deshalb fest, weil von einem ususfructus, welchem das Prädikat nullus beigelegt wird, nicht gesagt werden kann, er sei iure constitutus, da nullus gerade das Gegenteil von iure constitutus bedeutet. Man ist also genötigt, zu übersetzen: "so ist kein ususfructus an diesen Dingen nach dem geltenden Rechte bestellt worden." Trotz dieser Übersetzung ist der Eingang der Stelle nicht zu beseitigen, wonach allerdings ein ususfructus an "diesen Dingen" vermacht worden war; ein deutliches Argument, daß der Tatbestand des legatum ususfructus als vorhanden gedacht wird, mit den Worten nullus ususfructus iure constitutus videtur also die Rechtswirksamkeit dieses Tatbestandes, die ihm ohnedies, d. h. wenn er res non consumtibiles zum Objekt gehabt hätte, innewohnen würde, verneint werden soll.

1. 29 D. 23. 3. Ulp. I. 36 ad Sabin.: Cum pater dotem pro filia promittit et dotem legat, si quidem marito legavit, videndum est, an legatum valeat, et puto non valere: nam cum creditori debitor legat id quod debet, nullum legatum est.

Hier wird noch präziser als im vorigen Falle von einem Tatbestande des Legates gesprochen, der keine Kraft hat und bezw. der kein Legat ist, letzteres offensichtlich in dem Sinne, daß unter dem Legat einerseits der Tatbestand, anderseits die Wirkungsfähigkeit desselben verstanden werden will.

1) So auch Leonhard a. a. O. S. 388 N. 4 mit dem Bemerken, hier, wo der Sinn nicht zweifelhaft sei, sei allerdings nicht ersichtlich, ob nullum adjektivisch oder prädikativisch auftrete. 
1. $22 \S 4$ D. 35. 2. Paul. I. 17 quaest.: Sed si alii hoc nomen legetur nullum legatum erit nec ceteris contribuetur. Es ist die Rede von der Forderung gegen einen insolventen Schuldner. Wird dieselbe als liberatio dem Schuldner selbst legiert, so kommt es mit dem vollen Betrage bei Berechnung der Falcidia in Betracht (1. $22 \S 3$ ); wird es dagegen als nomen einem Dritten zugewendet, so spielt es bei Berechnung der Falcidia keine Rolle, weil es z. Z. des Todes keinen Vermögenswert darstellt. Insofern ist also die Hinterlassung dieses nomen ein Tatbestand ohne die sonst einem solchen zukommende Wirkungsfähigkeit, die Anwendung des falzidischen Gesetzes zu begründen. Insofern liegt also kein wirkungsfähiges Legat vor. Dagegen besteht kein Grund, die Wirksamkeit nach der Richtung hin zu bezweifeln, daß der Legatar die actio gegen den Schuldner anstellen und bei später eintretender Solvenz das Geschuldete beitreiben kann.

I. 35 \$ 5 D. 39.6 : $1.10 \S 1$ D. 37.5 . Ulp. 1.40 ad edict.: ... si nurui dotem praelegaverit eaque mortis tempore nupta sit, nullum legatum est, quia dos nondum debeatur....

Die Stelle handelt von einem praelegatum dotis im engern Sinne des Wortes, d. h. von dem Legat, durch welches der Ehemann oder dessen paterfamilias die in seiner Hand befindliche Dos der rückforderungsberechtigten Frau vermacht. Ist der Ehemann selbst Vermächtnisgeber, so wird mit seinem Tode die Frau, weil dadurch die Ehe aufgelöst wird, stets rückforderungsberechtigt. Das Legat hat sohin als legatum dotis debitae Wirkungsfähigkeit, insofern die Frau sofortige Restitution ohne Rücksicht auf die gesetzlichen Fristen verlangen kann.

Wenn dagegen das Legat vom Schwiegervater ausgeht, so fragt es sich, ob bei seinem Tode die Ehe noch besteht oder nicht. Ersterenfalls ist die Frau noch nicht rückforderungsberechtigt, folglich hat dies Legat der dos debita keinen Gegenstand, daher auch keine Wirkungsfähigkeit; es liegt zwar der Tatbestand eines Legats vor, aber dieser Tatbestand ist $\mathrm{kein}$ wirkungsfähiger. 
1. $1 \S 1$ D. 41.6. Paul. 1. 54 ad edict.: Si pater filio, quem in potestate habet, donet, deinde decedat, filius pro donato non capiet usu, quoniam nulla donatio fuit. cf. Vat. fr. \$ 292.

Der Tatbestand der donatio ist vorhanden; er ist aber kein rechtswirksamer Tatbestand, wie er es wäre, wenn der Beschenkte nicht in potestate des Schenkers stünde; das zeigt sich u. a. in der Unfähigkeit des Schenkungsaktes, als Ersitzungstitel zu dienen. Vgl. 1.27 D. 41.3.1)

1. $11 \S 1$ D. 18.1. Ulp. 1.28 ad Sabin.: ... ceterum si ego mulierem venderem, tu puerum emere existimasti, quia in sexu error est, nulla emptio, nulla venditio est.

Wie auch sonst die Stelle erklärt werden mag, das eine ist nicht zu leugnen, daß sie von dem Falle ausgeht, wo eine Kaufs- und Verkaufserklärung bezüglich eines Sklavenindividuums stattgefunden hat. Auch wenn man mit Leonhard ${ }^{2}$ ) hier das männliche Geschlecht des Kaufobjekts als zur stillschweigenden Geschäftsbedingung gesetzt denkt, muß man doch zugeben, daB der Tatbestand einer emtio, venditio, wenngleich condicionalis als vorhanden erachtet wurde. Aber keine wirkungsfähige emtio, venditio liegt vor, si in sexu erratur.

1. 15 p. D. 18. 1. Paul. 1. 5 ad Sabin.: Etsi consensum fuerit in corpus, id tamen in rerum natura ante venditionem esse desierit, nulla emptio est.

Wo alle Voraussetzungen des Vertrags zutreffen, da wollte gewiß nicht gesagt werden, der Tatbestand des Vertrags fehle; nulla emptio est kann also nicht bedeuten: es ist kein Tatbestand des Vertragsschlusses vorhanden, sondern nur: es ist kein wirkungsfähiger Vertrag vorhanden.

1. 6 \$ 3 D. 17. 1. Ulp. I. 31 ad edict.: Rei turpis nullum mandatum est et ideo hac actione non agetur.

Daß eine res turpis zu besorgen zugemutet und daß solche Zumutung angenommen wird, stellt den Tatbestand

1) Hieraus ergibt sich gegen Leonhard (a. a. O. S. 389), daß die Behauptung, die Quellen ließen durchweg bei entschuldbarer Unkenntnis nichtige Geschäfte als Titel gelten, nicht zutrifft. ${ }^{2}$ ) a. a. 0. S. 456 . 
eines Mandates dar, welches wirksam wäre, wenn nicht eben der Zweck auf eine res turpis ginge. Wegen dieses Zwecks ist kein wirksames Mandat gegeben und diese Wirkungslosigkeit zeigt sich in dem Versagen der actio mandati. Wollte mit nullum m. est gesagt werden: der Tatbestand des Mandats fehlt, so war es mehr als überflüssig, auch noch zu versichern: ideo hac actione non agetur; das wäre nicht besser, als wenn der Jurist ausgesprochen hätte: wo ein Darlehen vorliegt, kann die Mandatsklage nicht gestellt werden.

l. 54 p. D. 17. 1. Papin. 1. 27 quaest.: Si servus se extero mandat emendum, nullum mandatum est setzt ebenso wie 1. 1 p. C. 4.36 die Existenz des Tatbestandes voraus; wenn sie doch entscheidet, es sei kein Mandat vorhanden, so heißt dies wiederum nur: kein wirkungsfähiges, wie denn auch die Kodexstelle in Parenthese ausdrücklich bemerkt: 'quia hoc liber mandare non potest' und 'quoniam qui mandat, ut a se res comparetur, inutiliter mandat'. Daß inutilis die Wirkungslosigkeit bezeichnet, nimmt natürlich auch Leonhard ${ }^{1}$ ) an; dab aber mandare non potest nicht die faktische Unmöglichkeit der Herstellung des Mandatstatbestandes feststellen will, darüber s. Bd. XXIII S. 418.

1. $34 \S 1$ D. 18.1. Pomponius 1. 33 ad Sabin.: Omnium rerum, quas quis habere vel possidere vel persequi potest, venditio recte fit; quas vero natura vel gentium ius vel mores civitatis commercio exuerunt, earum nulla venditio est. Die letzten Worte der Stelle bilden den Gegensatz zu den vorausgehenden: venditio recte fit, bedeuten daher soviel als venditio non recte fit, es besteht kein wirksamer Verkauf, während der Tatbestand des Verkaufs, abgesehen von seiner Wirksamkeit, damit nicht geleugnet wird. Dafür zeugt auch

1. 1 C. 9.19. Gordianus 240: Res religioni destinatas, quin immo religionis effectas, scientes qui contigerint et emere et distrahere non dubitaverint, tametsi iure venditio non subsistat, laesas tamen religionis in crimen inciderunt.

1) a. a. $0.297,98$. 
Auch I. 11 C. 9.20 spricht von venditio plagio abducti, durch die freilich der status keine Veränderung erleidet.

So wenig also für die Bedeutung von nullus auf die adjektivische Stellung des Wortes ankommt, so unzutreffend ist das Beispiel, welches Leonhard ${ }^{1}$ ) gibt, um den Gegensatz des nicht vorhandenen zum nichtigen Geschäfte zu erläutern: „Ein Vertrag, bei dem ein Haus für nichts überlassen wird, ist z. B. nicht ein nichtiger Kauf, vielmehr gar keiner, sondern eine Schenkung." Gegenüber der These von der prädikativischen Bedeutung des Wortes nullus hätte das Beispiel nicht unglücklicher gewählt werden können. Denn sowohl in 1.46 D. 19.2 als auch in $1.10 \S 2$ D. 41.2 , beide aus Ulpian 1.69 ad edict., wird von conductio nummo uno ausgesagt: nulla est, und in $1.16 \S 1$ D. 4,4. Ulpian 1.11 ad edictum findet sich: nullam esse societatem non societas donationis causa coita.

Vgl. ferner :

1. $32 \S 24$ D. 24.1: Si ... societas donationis causa contracta sit, iure vulgato nulla est.

l. 35 \&5 D. 39.6: Si quis societatem per donationem mortis causa inierit, dicendum est nullam societatem esse.

Abgesehen von diesem Widerspruche des angeblichen Sprachgebrauchs mit dem Beispiel Leonhards erhellt aus einer Anzahl von Quellenstellen mit aller Deutlichkeit, daß gerade bei simulierten Geschäften der Geschäftstatbestand als gegeben angenommen und demselben die Wirkungsfähigkeit abgesprochen wird. Man vergleiche:

1. $5 \$ 1$ D. 17. 2. Ulp. 1.31 ad edict.: ... donationis causa societas recte non contrahitur.

1. 54 D. 44. 7. Modestinus 1.5 regular. Contractus imaginarii etiam in emtionibus iuris vinculum non optinent, cum fides facti simulatur non intercedente veritate.

1. 12 D. 39. 3. Paul. 1. 16 ad Sabin.: 'simulata venditio.'

1. 20 C. 5. 16: 'imaginariae factae venditioni.'

1) a. a. O. S. 297. 
1. 3 C. 4. 38 : 'venditionis simulatus contractus.'

1. 10 C. eod.: 'simulatam (emtionem).'

1. 38 D. 18.1. Ulp. 1.7 disput.: . . totiens enim dicimus in totum venditionem non valere, quotiens universa venditio donationis causa facta est. ${ }^{1}$ )

Daß nullus überall da, wo es sich um ein Urteil über die Wirkungsfähigkeit eines Tatbestandes handelt, auf den Mangel dieser Wirkungsfähigkeit und nicht auf den Mangel eines Tatbestandes hinweist, zeigt die Menge von Entscheidungen, in welchen die nämlichen Tatbestände, von denen anderwärts gesagt wird, daß sie nulla seien, mit Wendungen sich verbunden finden, welche zugestandenermaßen nur ausdrücken können, es fehle dem Tatbestand die Wirkungsfähigkeit. So heißt es in $1.14 \$ 1$ i. f. D. 7.8. Ulp. 1.17 ad Sabin.: ... sed si usufructu legato usus adimatur, nullam esse ademptionem, nachdem im Vorausgehenden gesagt worden war: denique si tibi fructus deducto usu legatus sit, inutile esse legatum ... In 1.14 \$ 1 D. 34.4: Florentinus 1. 1 instit. aber: Quibus ex causis datio legati inutilis est, ex isdem causis etiam ademptio inefficax habetur, so dab also die ademptio usus, weil datio fructus sine usus inutile legatum sein würde, ebensogut als inefficax hätte bezeichnet werden können.

In 1. 12 p. D. 23. 3. Ulp. l. 34 ad Sabin. wird zuerst die post contractum matrimonium erfolgende adprobatio aestimationis einer zur dos gegebenen Sache, wo die adprobatio donationis causa geschieht, als aestimatio nulla erklärt unter Bezugnahme darauf, daß auch eine distractio donationis causa unter Eheleuten unmöglich sei; und diese Unmöglichkeit selbst wird mit den Worten erläutert: cum effectum i. v. e. u. non habeat.

Die donatio patris familias in filium collata wird in Vat. fr. $\S \S 292$ und in $1.1 \S 1$ D. 41.6. Paul. 1.54 ad edict. nulla donatio genannt, in Vat. fr. $\S 295$ wird von derselben bemerkt: nullius esse momenti.

1) Zum Sprachgebrauch von nullus s. auch Lotmar in der Krit. V. J. Schr. Bd. 7 N. F. S. $248 ; 49$. 
Von der um bestehender Ehe willen unwirksamen donatio erklärt

I. 46 D. 24. 1. Ulp. 1.72 ad edict.: nec ... ulla donatio est, 1. 53 p. D. eod. Papin. 1. 4. respons. .... frustra donare convenit.

In 1. 40 p. D. 13. 7. Papin. 1. 3. respons. und in 1.22 $\S 3$ D. 17.1. Paul. 1. 32. ad edict. erscheint die emtio der eigenen Sache des Käufers als nulla emptio, welche ebenfalls in 1.40 p. cit. und in 1.4 C. 4.38 durch frustra emere, in 1.16 p. und 1.18 p. D. 18.1. Pompon. l. 9. ad Sabin. durch non valere charakterisiert wird und von welcher endlich 1. 39 p. D. 18.1. Julian 1. 15. digest. entscheidet ... emtor actione ex vendito non tenetur.

Ebenso ist der Kauf einer res divini iuris nach 1. 22 D. 18.1. Ulp. 1. 28. ad Sabin. nulla emptio, während $\$ 5$ J. 3.23 von frustra emere sprechen. Bei mangelndem Konsens der Kontrahenten in corpore ist nach 1.9 p. D. 18.1. Ulp. 1. 28. ad Sabin. emptio nulla; 1. 55 D. 44. 7. Javolen. 1. 12. epistol. drückt den gleichen Gedanken aus durch: perduci ad effectum id quod inchoatur non potest.

Während das legatum debiti in 1. 29 D. 23. 3. Ulp. 1. 36. ad Sabin. als legatum nullum auftritt, wird in 1.67 p. D. 31 . Papin. 1. 19 quaest. von dem Vermächtnisgeber im gleichen Falle ausgesprochen: frustra legat.

Das praelegatum dotis des Schwiegervaters zu gunsten der Schwiegertochter heißt nullum in $1.10 \S 1$ D. 37.5. Ulp. l. 40. ad edict., nullius momenti in $1.1 \S 9$ D. 33.4 . Ulp. 1. 19. ad Sabin.

Die Wirkungslosigkeit eines legatum nominis non existentis wird in der nämlichen Stelle, 1. $75 \& 1$ D. 30. Ulp. 1. 5. disput. einmal durch nullum esse legatum und unmittelbar darauf durch nihil debebitur ausgedrückt.

Die Nullität der fideiussio besteht nach 1.37 D. 46.1. Paul. 1. 17. ad Plautum darin, daß fideiussor non tenetur, die des Mandats nach 1. $6 \$ 3$ D. 17.1 (oben S. 56) darin, dab hac actione non agetur, wozu Gai. III. $157 \mathrm{zu}$ vergleichen, der von dem mandatum contra bonos mores nicht etwa erklärt, daß es den Tatbestand eines Mandats nicht enthalte, sondern: non contrahi obligationem. 
Die stipulatio sub impossibili condicione wird in 1.9 $\$ 6$ D. 12. 1. Ulp. 1. 26. ad edictum nulla genannt, nach 1.31 D. 44. 7. Maecianus l. 2. fideicommiss. ist sie nullius momenti, nach $\$ 11$ J. 3.19 wird von ihr ausgesagt: non valet.

Promittiert ein furiosus, so ist die stipulatio nulla nach l. 70 \$ D. 46.1. Gai. 1. 1. de verb. obl.; l. 1 \$ 12 D. 44.7. Gai. 1. 2. aureorum drückt den gleichen Gedanken aus durch: nihil agere (furiosum) natura manifestum est.

1. 19 D. 28. 1. Modestin. 1. 5 pandect. bezeichnet die tabulae testamenti, quas is fecit, qui testamenti faciendi facultatem non habuerit, als nullae; nach 1.8 p. D. eod. Gai. 1. 17. ad edict. prov.: eius qui apud hostes est testamentum quod ibi fecit non valet, quamvis redierit.

Ebenso wie nullum esse sich auf die Wirkungsfähigkeit eines Tatbestandes bezieht, werden auch non esse, non posse intellegi, locum non habere und Synonyma verwendet, um die Wirkungsfähigkeit eines Tatbestandes zu verneinen, dem der Regel gemä乃 Wirkungsfähigkeit zukommt, nicht aber um das Vorhandensein des Tatbestandes selbst in Abrede zu stellen.

In der Durchstreichung letztwilliger Verfügungen, welche in einer Testamentsurkunde enthalten sind, liegt z. B. eine Handlungsweise, welche den Tatbestand des Widerrufs darstellt. Doch gehört zur Wirkungsfähigkeit desselben das Bewußtsein des Handelnden, daß er die Durchstreichung vornehme. Eine unabsichtliche, z. B. infolge einer Unvorsichtigkeit vollzogene Durchstreichung hat nicht die Fähigkeit, das Durchstrichene außer Kraft zu setzen, auch nicht dann, wann der Testator seinem Testamente den Zusatz gegeben hat: 'lituras, inductiones, superductiones ipse feci.' Daher konnte l. 1 pr. 28. 4. Ulp. 1. 15. ad Sabin. wohl aussprechen: ... proinde et si inconsulto superseripsit, induxisse se, manebunt et sic adempta ${ }^{1}$ non erunt adempta.

Eine Erbeseinsetzung von der Fassung: 'ex his partibus, ex quibus testamento matris scripti fuissent, heredes sunto" ist als bedingte Einsetzung zu erachten; vgl. 1. 2 p. D. 28. 5.

1) So Mommsen statt 'et si ademit', ohne $\operatorname{daß} \operatorname{der}$ Sinn hierdurch sich verändert. 
Ulp. 1. 2. ad Sabin. Von der bedingten Einsetzung aber steht fest, daß sie selbst nach Ausfall der Bedingung als Testament gilt, insofern ein früheres Testament dadurch aufgehoben wird. Trotzdem finden wir in $1.2 \S 1$ i. f. cit. 'si intestata mater decesserit, hos non esse institutos'. Diese Worte können demnach nicht bedeuten, daß keine Einsetzung stattgefunden habe, sondern daß die stattgehabte Einsetzung die Wirkung, welche sonst nach dem Tode des Testators der (unbedingten) Einsetzung zukommt, nicht zu äußern vermöge.

Wenn in $1.110 \S 2$ D. 50.17 die regula iuris aufgestellt wird: 'Pupillus pati non intelligitur', so ist klar, daß hiermit nicht die faktische Möglichkeit der Duldung seitens eines Pupillen geleugnet werden wollte. Freilich ein pati mit der Wirkung eines Rechtsnachteils ist seitens eines Pupillen nicht möglich. So nicht das Dulden eines Sklavendelikts mit der Wirkung, daß actio legis Aquiliae gegen den dominus pupillus begründet würde (l. 3 D. 9.4), so nicht die Duldung eines nachbarlichen opus mit der Wirkung des Verlustes der aquae pluviae arcendae actio (l. 19 D. 39.3).

l. 32 § 2 D. 4. 8. Paul. l. 13. ad edict. kann unmöglich den Tatbestand des Kompromisses leugnen wollen mit den Worten: non erit pecunia compromissa, da sie ihn geradezu voraussetzt, wenn sie vorher sagt: Si mulier alieno nomine compromittat. Indem sie zu non erit pecunia compromissa hinzufügt: propter intercessionem, spricht sie aus, daB der Tatbestand des Kompromisses intercedendi causa gegen die kompromittierende mulier der verpflichtenden Wirkung wegen des SC Velleianum entbehre.

Ebensowenig wird in 1.20 D. 12.1. Iulian. l. 18. digest. durch neque donationem esse neque pecuniam creditam und durch non fore creditam keineswegs der Schenkungs- und der Darlehnstatbestand in Abrede gestellt, sondern lediglich auf seine Wirksamkeit (valere) geprüft.

Auch 1.8 p. D. 18.1. Pomp. 1.9. ad Sabin.: Nec emptio nec venditio sine re quae veneat posse intellegi verneint nur die Wirkung des Kaufvertrags, nicht seine Existenz; sonst könnte nicht in $1.1 \mathrm{D} .18 .4$ von Pomponius in demselben Buche ad Sabin. gesagt worden sein: si hereditas venierit 
eius qui vivit aut nullus sit, nihil esse acti, quia in rerum natura non sit quod venierit, noch in $1.7 \mathrm{D}$. eod. Paul. 1. 14. ad Plaut:: Cum hereditatem aliquis vendidit esse debet hereditas, ut sit emptio: nec enim alea emitur, ... sed res: quae si non est, non contrahitur emptio.

Endlich ist in diesen Zusammenhang zu bringen 1.14 $\S 3$ D. 18. 2. Paul. 1. 5. ad Sabin. Die Auflösung des mit addictio in diem geschlossenen Kaufvertrags wird hier $u$. a. geleugnet, wenn die addictio, d. h. der Zuschlag zu besserem Gebote, also der spätere Verkauf, an den Eigentümer der Sache erfolgt ist mit der Begründung: quia non est emptio his casibus. Nun wurde aber bereits nachgewiesen (oben S. 60), dah die Quellen den Kauf der eigenen Sache zwar als ein frustra emere, als emtio quae non valet oder ex qua emtor actione ex vendito non tenetur qualifizieren, aber immerhin als ein emere, als eine emtio, daß sie also die Existenz des Tatbestandes emtio nicht bezweifeln oder gar verneinen, sondern nur seine Rechtswirkung.

Freilich kommt non esse bisweilen auch vor, um das Nichtvorhandensein eines Tatbestandes zu konstatieren. Dies ist aber überall nur da der Fall, wo es sich gar nicht um die Frage der Rechtswirkung eines bestimmten Tatbestandes handelt, sondern um die Beseitigung von Zweifeln, ob gewisse Tatsachen einen gewissen Tatbestand erschöpfen oder nicht. Es können die Umstände nämlich so gelagert sein, daß derartige $Z$ weifel auftauchen, und nur wo zu solchen Zweifeln äußerer Anlaß besteht, untersuchen die Quellen das esse oder non esse der Tatbestände. Das wird durch nachfolgende Quellenzeugnisse belegt:

1. 18 D. 12.1. Ulp. 1. 7. disput.: Si ego pecuniam tibi quasi donaturus dedero, tu quasi mutuam accipias, Iulianus scribit donationem non esse; ... et puto nec mutuam esse ...

§ 1: Si ego quasi deponens tibi dedero, tu quasi mutuam accipias, nec depositum nec mutuum est.

Es ist bezeichnend, daß hier der Jurist vorsichtig den Tatbestand beschreibt mit si ... quasi donaturus, quasi deponens dedero, während in jenen Stellen, wo es darauf ankommt, die Wirkungslosigkeit des Schenkungstatbestandes, 
der unter andern Umständen wirksam wäre, festzustellen, gesagt wird: si donassem (1. 20 D. 12.1), frustra donare convenit (1. 53 p. D. 24. 1); ut in matrimonii tempus collata donatio videatur atque ideo non valet (l. 12 p. D. 23.3), si pater filio ... donet ... nulla donatio fuit (s. o. S. 62. 59. 55).

In der Tat fehlt es in den Fällen der 1. 18 cit. schon an der äußeren Erscheinung des Schenkungs- und des Darlehenstatbestandes. Denn dazu gehört Konsens über die causa donandi bezw. credendi, während hier Dissens, wenn auch nicht zum Bewußtsein kam, so doch objektiv vorlag. Folglich konnte hier höchstens die Zweifelsfrage auftauchen und entschieden werden, ob der den Parteien unbewulate Dissens über die causa den Tatbestand des vom Hingebenden intendierten Geschäftes erschöpfe oder des vom Empfänger beabsichtigten oder keinen von beiden; dagegen lag die Frage nach der Wirksamkeit oder Unwirksamkeit eines existenten Schenkungs- oder Darlehenstatbestandes gar nicht vor.

Ganz analog liegt der Fall der I. 23 C. 4. 65. Diocl. et Maxim. a. 293: Ad probationem rei propriae sive defensionem non sufficit locatio ei facta, qui post de dominio coeperit contendere, cum nescientia dominii proprii et errantis nullum habeat consensum ... Der Konsens, auf den es hier ankam, war der zwischen conductor und locator darüber, daß jener das Eigentum an der Sache diesem übertragen sollte. Vorausgesetzt wird die Unbekanntschaft des conductor mit seinem Eigentum; daraus wird mit Recht geschlossen: wer seine eigene Sache unbekannt mit seinem Eigentum mietet, kann dadurch nicht den Willen, sein Eigentum aufzugeben, ausdrücken, also auch nicht der Eigentumserwerbsabsicht des locator zustimmen. Folglich liegt der Tatbestand des Konsenses gar nicht vor. Nicht war es die Meinung der Kaiser, dem wirklich vorhandenen Konsens die Wirkung zu versagen.

Das Gleiche ist zu bemerken in 1.5 p. D. 5. 1. Ulp. 1. 3. ad edict.: Consensisse autem videntur, qui sciant se non esse subiectos iurisdictioni eius et in eum consentiant. ceterum si putent, eius iurisdictionem esse, non erit eius iurisdictio: 
error enim litigatorum .... non habet consensum. Über die Unterwerfung unter einen unzuständigen Prätor oder Präses einverstanden sein können die Parteien nicht, wenn sie ihn nicht für unzuständig halten. Man hätte vielleicht annehmen können, die beiderseitige Verhandlung vor dem unzuständigen Magistrat enthalte auch den eventuellen Konsens über die Unterwerfung unter seine Jurisdiktion. Dieser Meinung begegnet die Stelle. Solcher Konsens würde mindestens $Z$ weifel an der Zuständigkeit voraussetzen; wo aber, wie hier, der positive Glaube an die Zuständigkeit vorliegt, da ist die Möglichkeit jenes Konsenses ausgeschlossen. Mithin wird hier die Frage, ob vorhandener Konsens wirksam sei, gar nicht aufgeworfen.

Wie gesagt, findet sich non esse als Verneinung eines Tatbestandes in den Quellen nicht häufig. Die Regel ist die, non esse zur Verneinung der normalen Rechtswirkung eines Tatbestandes zu verwenden. Die Richtigkeit dieser Beobachtung geht noch deutlicher als aus den oben besprochenen Belegen, wo non esse im Sinne der Wirksamkeitsverneinung mit der Tatbestandsangabe verbunden auftritt, aus jenen Stellen hervor, wo nach Beschreibung eines Tatbestandes non esse direkt von seiner normalen Wirkung ausgesagt wird.

Man vergleiche:

1. 55 D. 18. 1. Paul. 1. 2. ad edict. aedil. curul.: Nuda et imaginaria venditio pro non facta est et ideo nec alienatio eius rei intellegitur.

Die Trivialität wäre doch zu stark, wenn der Jurist hätte sagen wollen: deshalb, weil der Tatbestand einer venditio nicht vorliegt, ist nicht anzunehmen, daß eine Veräußerung vor sich geht.

I. 31 D. 40. 4. Paul. 1. 26. ad edict. Cum ex pluribus eodem nomine servis unus liber esse iussus non appareat qui sit, nullus liber est.

l. 9 p. D. 40.9. Marcian l.1. instit.: Ille servus liber non erit, qui vi coegerit... ut eum dominus manumittat.

Gai. instit. I. 46. Si ... libertas data sit, nulli liberi erunt.

s. ferner 1.17 p. D. 40.9 ; 1. 2 D. 40.13. 
1. 30 D. 26. 2. Paul. 1. 6. quaest.: Duo sunt Titii; ... datus est tutor Titius .... neuter est tutor.

1. 63 D. 23. 2. Paul. 1. 1. defin. Praefectus cohortis vel equitum aut tribunus contra interdictum eius provinciae duxit uxorem, in qua officium gerebat: matrimonium non erit.

s. ferner 1. 66 D. eod.; $1.3 \S 1$ D. $24.1 ; 1.79$ (77) $\$ 1$ i. f. D. $36.1 ; 1.7$ D. 48.5 .

1. $42 \S 1$ D. 23. 2. Modestin., libro singul. de ritu nuptiarum. Si senatoris filia ... libertino vel qui artem ludicram exercuit ... nupserit, nuptiae non erunt.

s. ferner l. 68 D. 23.3 ; l. 27 D. 23.2 ; 1.5 C. 5.3.

l. $5 \$ 2$ D. 20.2 in fine. Marcian 1. singul. ad formulam hypothecar. .... sane si postea sint eius res hypothecae datae, non erunt obligatae.

I. $47 \S 1$ C. 1.3. Qui .... aliquos episcopos creare conabuntur ... neque episcopi erunt.'

Besonders charakteristisch ist aber für den Sprachgebrauch

1. $41 \S 3$ D. 28. 6. Papin. 1. 6. respons. ....... quae ita locum habent, si patris testamentum iure valuit; alioquin si non valuit, ea scriptura, quam testamentum esse voluit, codicillos non faciet, nisi hoc expressum est ....

Zunächst wird hier von dem Vorhandensein des Tatbestandes eines Testaments ausgegangen und bei diesem Tatbestande unterschieden, ob er Wirksamkeit habe oder nicht. Für den letzteren Fall wird der Tatbestand als nicht existent bezeichnet; denn es wird nicht mehr von testamentum, sondern von ea scriptura, quam - voluit, also von einer Schrift, die Testament sein sollte, d. h. doch wohl "nicht ist" gesprochen. Deutlicher könnte nicht hervortreten, daß durch Nichtexistenz" die mangelnde Rechtswirksamkeit ausgedrückt wird.

Mit den gewonnenen Ergebnissen steht nicht im Widerspruch die Bedeutung, in welcher imperfectus in den Quellen auftritt. Das Wort findet sich bei letztwilligen Verfügungen sowohl als bei Tatbeständen inter vivos. In Verbindung mit ersteren kommt es in folgenden Stellen vor: 
1. 18 D. 33. 2. Modestinus 1. 9. respons. Qui plures habebat libertos, testamento suo dixit se habitationem relinquere iis quos codicillis designasset: cum nullos postea designaverit, quaero, an omnes admitti debeant. respondit ... legatum perfectum esse non videtur non existente cui datum intellegi possit.

1. $2 \S 1$ D. 29.3. Ulp. 1. 50. ad edict.: Testamentum autem proprie illud dicitur, quod iure perfectum est: sed abusive testamenta ea quoque appellamus, quae falsa sunt, vel iniusta vel irrita vel rupta: itemque imperfecta solemus testamenta dicere.

1. 38 D. 40.5. Paul. 1. 3. decret.: In testamento quod perfectum non erat alumnae suae libertatem et fideicommissa dedit. cum omnia ut ab intestato egissent, quaesiit imperator, an ut ex causa fideicommissi manumissa fuisset: et interlocutus est: etiamsi nihil ab intestato pater petisset, pios tamen filios debuisse manumittere eam, quam pater dilexisset. pronuntiavit igitur recte eam manumissam et ideo fideicommissa etiam ei praestanda.

1. 2 D. 28. 3. U]p. 1. 2. ad Sabin.: Tune autem prius testamentum rumpitur, cum posterius rite perfectum est, nisi forte posterius vel iure militari sit factum vel in eo scriptus est, qui ab intestato venire potest. tunc enim posteriore non perfecto superius rumpitur.

1. 26 C. 3. 36. Constantinus a. $321=1.1$ C. Th. 2. 24. ${ }^{1}$ ) .... sive coeptum neque impletum testamentum... memoratur ... defuncti dispositio custodiatur.

l. $21 \S \S 2^{a} .3$ C. 6. 23. Theodos, et Valentin. a. 439. Finem autem testamenti subscriptiones et signacula testium esse decernimus. non subscriptum namque a testibus ac signatum testamentum pro imperfecto haberi convenit. Ex imperfecto autem testamento voluntatem defuncti, nisi inter solos liberos .... habeatur, non volumus $=$ Nov. Theod. tit. XVI. § 5. (corpus iuris anteiust. ed. Hänel II. p. 62. 63.)

1. $21 \S 5$ eod. $=$ Nov. Theod. cit. $\S 7$. Si quis autem testamento iure perfect o postea ad aliud pervenerit testamentum non alias quod ante factum est infirmari decerni-

1) Vgl. Fein in Glücks Erl. Bd. 45. S. $229 \mathrm{ff}$. 
mus, quam id, quod secundum facere testator instituit, iure fuerit consummatum, nisi forte ..... eo enim casu licet imperfecta videatur scriptura posterior ... secundam eius voluntatem .... valere sancimus.

1. 16 C. 3. 28. Valerian. et Gallien. a. 258. . . . duplicem actionem inferentes, primam quasi testamentum non iure sit perfectum .....

In einem Teile dieser Gesetze begegnet uns lediglich der Ausdruck imperfectum, indem seine Bedeutung anderweitig als bekannt vorausgesetzt wird.

Dahin gehören $1.2 \S 1$ D. $29.3 ; 1.38$ D. 40. 5; I. 2 D. 38.3 ; I. 16 C. 3.28. Diese sind daher zur Feststellung der Bedeutung nicht verwertbar.

Von den übrigen angeführten Quellenzeugnissen handelt ein einziges von dem legatum imperfectum, die übrigen haben das testamentum imperfectum zum Gegenstande.

Das Legat wird in I. 18 D. 33.2 imperfectum genannt, weil die Anordnung des Erblassers nicht ersehen läbt, welcher Person er einen Vorteil zuwenden will.

Von testamentum imperfectum spricht I. 21 §§ $2^{\mathrm{a}} \cdot 3$ C. 6. $23 \mathrm{im}$ Hinblick auf den Mangel von Unterschrift und Siegelung der Testamentsurkunde seitens der Zeugen. Da diese Akte nach demselben Gesetze den finis testamenti ausmachen, so folgt, daß ein testamentum imperfectum umsomehr vorliegt, wenn eine zum Errichtungsakte erforderliche Handlung fehlt, die dem Schlußakte vorauszugehen hat, z. B. die Unterschrift des Erblassers. Wo diese fehlt, kann die Unterschrift und Siegelung der Zeugen die Perfektion nicht herstellen; denn sie sind finis testamenti nur da, wo sie sich dem initium anschließen, nicht, wo dieses fehlt. Dies ergibt sich auch aus $\S 5$ durch den Gegensatz von iure consummatum und imperfecta scriptura. Denn consummatum bezeichnet die Vollendung in allen einzelnen Teilen.

Man darf überdies aus l. 18 D. 33.2 ohne weiteres auch auf das Testament schließen und annehmen, daß ein Testament als imperfectum gilt, wenn in demselben die Person des oder eines Erben nicht ersichtlich gemacht wird. Man vgl. hierzu 1. 25 D. 28.1. Noch deutlicher folgt aber die Bedeutung des "Mangels irgend eines Formerfordernisses" für das Wort imperfectum aus 
l. 2 D. 28. 3; denn, wie Mühlenbruch in Glücks Erl. Bd. 38. S. 366-371 und Leist. bon. possessio II. 1. S. 283. II. 2 S. 101 gezeigt haben, bezieht sich dies Fragment auf den Gegensatz des Manzipationstestaments zum prätorischen Testament. Das letztere ist imperfectum gegenüber dem ersteren, weil es nicht allen Formerfordernissen der Errichtung nach ius civile entspricht.

Wie für letztwillige Verfügungen wird der Perfektionsbegriff für die Schenkung nach dem Rechte der 1. Cincia verwendet. Vat. fr. $\S 275$. 287. 312. 1. 4 C. 8. 55 .

Tatbestände inter vivos mit dem Prädikate imperfectus bezeichnet finden sich in:

1. 9 pr. D. 18.1. Ulp. 1. 28. ad Sab. . . sive in ipsa emtione dissentiant, sive in pretio sive in quo alio, emtio imperfecta est.

1. 115 pr. D. 45. 1. Papin. I. 2. quaest.: Ita stipulatus sum: 'te sisti in certo loco. si non steteris 50 aureos dari spondes?' si dies in stipulatione per errorem omissus fuerit, cum id ageretur, ut certo die sisteres, imperfecta erit stipulatio non secus ac si quod pondere numero mensura continetur sine adiectione ponderis numeri mensurae stipulatus essem, vel insulam aedificari non demonstrato loco, vel fundum dari non adiecto nomine .....

Hierher gehören weiter:

1. 8 p. D. 18.6. Paul. I. 33. ad edict.: ... et si id quod venierit appareat, quid quale quantum sit et pretium et pure veniit, perfecta est emptio ...

Denn danach ist emtio imperfecta, wenn quid oder quale oder quantum oder pretium oder puritas fehlt. ef. 1.1 C. 11. 32 (31); 1. 21 \& 7 D. 50.1 ; $1.5 \& 1$ C. $4.44 ; 1$ l. 3. eod.

Aus dem Vergleiche dieses Materials muß der Schlußs gezogen werden, daß in demselben das Prädikat imperfectus auf privatrechtlichem Gebiete ${ }^{1}$ ) nur solchen nicht deliktischen Tatbeständen beigelegt wird, welche in Willensäußerungen bestehen. Ferner daß es nur verwendet wird, um anzuzeigen, es sei

a) bei letztwilligen Anordnungen zwar eine Willensäußerung erfolgt, es fehle aber entweder an der Echtheit

1) Vgl. übrigens $1.1 \S 2$ D. 2.2 . 
oder an einem Formerfordernisse oder an der Beobachtung der Vorschriften des zivilen Noterbenrechtes oder endlich an der deutlichen Bezeichnung des begünstigten Subjektes.

b) bei Willenserklärungen inter vivos zwar eine Willenserklärung abgegeben worden, deren Absicht auf die Herstellung eines bestimmten Tatbestandes hinweist, es fehle ihr aber

entweder an der erforderlichen Annahme von der Gegenseite (Konsens)

oder an der erforderlichen Bestimmtheit in der Richtung auf ihr Objekt

oder an der Unbedingtheit. ${ }^{1}$ )

Überall handelt es sich in erster Linie darum, festzustellen, daß das Geschehene nicht ausreicht, um den Tatbestand zu erfüllen, auf den die Absicht des Erklärenden hinzielt. Denn der in die Außenwelt getretenen Erscheinung nach könnte dies zweifelhaft sein. Daß die normale Wirkung jenes Tatbestandes in solchen Fällen nicht eintritt, ist etwas Sekundäres, das allerdings gewöhnlich in Verbindung mit der Feststellung der Unvollkommenheit ausgesprochen wird.

1. 9 pr. cit.; 1.115 p. cit.

Sprachlich bleibt es korrekt, von der Existenz des Tatbestandes zu reden, obwohl er unvollendet ist. Denn es springt in die Augen, daß der unvollendete Tatbestand durch eine weite Kluft getrennt ist von der Nichtexistenz des Tatbestandes. Man könnte den unvollendeten Tatbestand mit dem Versuch des Verbrechens vergleichen, während die Nichtexistenz des Tatbestandes eine völlige Passivität voraussetzt.

Die Bezeichnung imperfectum findet sich gelegentlich auch zum Ausdrucke der Unwirksamkeit schlechthin verwendet:

I. 63 p. D. 18. 1. Iavolen. 1. 7. ex Cassio: Cum servo dominus rem vendere certae personae iusserit, si alii vendidisset, quam cui iussus erat, venditio non valet; idem iuris in libera persona est, cum perfici venditio non potuit in eius persona, cui dominus venire eam noluit.

1) Ganz anders Köppen, Lehrbuch des Erbrechts S. 419 ff. 
1. 14 D. 46. 4. Paul. 1. 12. ad Sab. Nisi consentiat acceptilatio cum obligatione et nisi verum est, quod in acceptilatione demonstratur, imperfecta est liberatio, quia verbis ea demum resolvi possunt, quae inter se congruunt.

Der Tatbestand des Kaufes bezw. des Acceptilationsaktes ist in den beiden Stellen vollständig; die Wirkung - der alienatio im ersten, der liberatio im zweiten Falle ist dagegen imperfekt, weil sie zwar herbeizuführen versucht wurde, dieser Versuch aber erfolglos blieb. Vgl. noch 1. 1 $\$ 2$ D. 2.2 (s. u. S. 82 Nr. 4).

Vereinzelt kommt imperfectus vor, um auszudrücken, daß eine obligatorische Verpflichtung zwar bestehe, aber noch nicht erfüllt worden sei $1.9 \S 3$ D. 4.2 entsprechend der Bedeutung von perficere als Vollziehen, Erfüllen einer obligatorischen Verpflichtung 1. 57 D. 18.1.

Hier ist die Auffassung, dals ein Tatbestand, durch welchen die Herbeiführung einer Vermögensleistung bezweckt wird, noch unvollkommen sei, solange der Zweck nicht durch die Leistung erreicht worden ist.

Jedenfalls wird auch in dieser Verbindung des Wortes von der Existenz des als imperfekt bezeichneten Tatbestandes ausgegangen.

Aus den obigen Untersuchungen über den Sprachgebrauch der Quellen läßt sich für die Terminologie, wenn ihr der Vorwurf, daß sie sich nicht für verpflichtet erachte, mit der Sprache der Quellen Fühlung zu halten ${ }^{1}$ ), erspart bleiben soll, die Folgerung ableiten, daß Tatbestände, welche aus besonderen Gründen die ihnen der Regel nach zukommende Rechtswirkung entbehren, mit demselben technischen Namen zu bezeichnen sind, der ihnen gebührt, wo sie jene Wirkung erzeugen. Auf die sogen. "Rechtsgeschäfte" angewendet führt diese Folgerung dahin, Tatbestände, welche man als Rechtsgeschäfte bezeichnen zu müssen glaubt, wenn sie eine bestimmte Rechtswirkung äußern, Rechtsgeschäfte auch da zu nennen, wo ihnen diese Wirkung aus besonderen Gründen abgeht. Vgl. hierzu Brinz-Lotmar,

1) Bekker, Couponprozesse S. 36 Amm. 
Pand. 2a. Bd. 4. S. 397 Nr. 3: „Diese 'mißbräuchliche' Benennung kommt so häufig vor, daß man von Sprachgebrauch reden muß." Lotmar hatte schon früher ${ }^{1}$ ) diesen Sprachgebrauch nachgewiesen und ihn so formuliert: „man verleiht das Prädikat, das einem Vorgange in den Augen des Rechts zukommen würde, wenn er diesem so erschiene, wie er dem Handelnden erscheint, auch dann, wenn es dem Vorgange an Rechtswirkung gebricht."

DaB Lotmar den Sprachgebrauch auf animi destinatio zurückführt, kann beanstandet werden im Hinblick auf das simulierte Geschäft, für das wir dem gleichen Sprachgebrauch begegnen (s. o. S. 58 f. 65), sowie angesichts von Fällen wie l. 18 i. f. D. 8. 4. 'inutiliter dies legati cedit' oder 1.2 \& 2 D. 40. 15. 'praescriptio quinque annorum ... non fit irrita', bei denen von animi destinatio überhaupt nicht die Rede sein kann. ${ }^{2}$ )

Lotmar $^{3}$ ) bemerkt auch mit Recht gegen Bülow ${ }^{4}$ ) unter Bezugnahme auf Exner ${ }^{5}$ ), es sei keineswegs eine "entsetzliche Rechtsvorstellung", daß man das Nichtdasein im Rechtssinne oder die Nichtigkeit als eine „Eigenschaft von etwas (im faktischen Sinne) Existierenden" hinstellt; denn man dürfe doch Dasein für das Recht und Dasein für die Welt des Faktischen unterscheiden. ${ }^{6}$ ) -

Zum Unterschiede von den Normalfällen mag man solche Tatbestände, denen die normale Wirkung gänzlich fehlt, „unwirksam" oder "nichtig" nennen.")

Man wendet nun allerdings ein ${ }^{8}$ ): Jede Rechtswirkung setze einen bestimmten Tatbestand voraus, an welchen dieselbe vom Recht geknüpft wird. Derselbe bestehe in der Gesamtheit aller juristischer Voraussetzungen der Rechtswirkung und werde keineswegs schon erschöpft durch die Umstände, welche die systematische Betrachtung als Merkmale der einzelnen Gattungen und Arten der Rechtstat-

1) Über causa S. 11-13. - ${ }^{2}$ ) Vgl. Zitelmann, Irrtum S. 287. 299. 300. - ${ }^{3}$ ) Bei Brinz a. a. O. S. 396 N. 1. - ${ }^{4}$ ) Arch. f. d. civ. Pr. 62 S. 77. - 5) Tradition S. 285 Anm. 105. - ${ }^{6}$ ) Vgl. Bechmann, Kauf I. S. 548. II. S. 13. Endemann, Verbotsgesetze S. 77, der freilich den Einwänden Schloßmanns (s. unten zu N. 8) eine gewisse Berechtigung zugesteht; Hölder, Pand. S. 305 Anm. 1. - ') So Le onhard, Der Irrtum etc. S. 296. - \$) Schloßmann, Zur Lehre vom Zwang S. $12 \mathrm{ff}$. 
sachen, z. B. der Verträge und deren Klassen, der Delikte, des Testaments aufstellt. Einen vollen rechtlichen Tatbestand erhielten wir erst, wenn wir mit den Merkmalen der individuellsten Objekte der systematischen Betrachtung all dasjenige verbinden, was in allgemeinen Regeln und Lehrsätzen auch für sie prädiziert worden sei. So sei es auch beim sog. "Rechtsgeschäft". Im System trete es auf losgelöst von zahlreichen Voraussetzungen, ohne deren gleichzeitiges Vorhandensein eine Rechtswirkung niemals eintreten könne. Sobald es aber in praktischer Beziehung in Frage komme, müsse es jene künstlich geschaffene Selbständigkeit aufgeben und könne nur noch als ein unselbständiger Teil in dem gesamten Komplex der für die konkrete Rechtswirkung erforderlichen tatsächlichen Voraussetzungen behandelt werden. Wie es in der Natur für den Eintritt einer bestimmten Wirkung völlig gleichgiltig sei, ob von der Gesamtheit ihrer notwendigen Ursachen alle oder eine fehlten, so sei auch ein juristischer Tatbestand nicht vorhanden, wenn es nur an einem seiner Momente gebreche.

Gegen die Logik dieser Ausführung wird sich nichts erinnern lassen. Allein auf diese Logik kommt es nicht an, wenn nicht zugleich feststeht, daß die Rechtswissenschaft (natürlich einschlieblich der Rechtsprechung) von der Betrachtungsweise ausgehen müsse, die den obigen Einwendungen zu grunde liegt. Dieser Betrachtungsweise erscheinen alle tatsächlichen Voraussetzungen, welche das Recht für eine konkrete Rechtswirkung aufstellt, gleichartig. Sie übersieht dabei aber; dab dieselben sich in zwei verschiedene Arten tatsächlich zerspalten ${ }^{1}$ ): solche, welche in die äußere Erscheinung treten, also für jedermann wahrnehmbar sind, der sich in Gesichtsweite befindet ${ }^{2}$ ), und solche, welche eine Veränderung in dem bestehenden Zustande der Dinge nicht mit sich bringen, also der äußeren Erscheinung und Wahrnehmung sich entziehen. Vergleichen wir z. B. das Testament, so finden wir als Voraussetzungen seiner Rechtswirkung:

1) cf. Eisele, Die materielle Grundlage S. 79 zu Nr. 34. 2) Zitel mann, Irrtum S. 287. Burckhard, Die civilist. Präsumtionen S. 156. s. Langenbeck, Die Beweisführung in bürgerl. Rechtsstreitigkeiten II S. 280 '1. 
einerseits die Äußerung eines Willens von bestimmter Form und bestimmtem Inhalt sowie den Tod des Erklärenden,

anderseits Testierfähigkeit des Testators, testamentifactio passiva des Eingesetzten, Überleben desselben, Beobachtung der Vorschriften des Noterbenrechts etc. etc.; oder nehmen wir den Kaufvertrag, so erfordert derselbe zu seiner Rechtswirksamkeit:

einerseits die Abgabe übereinstimmender Erklärungen über merx und pretium,

anderseits Handlungsfähigkeit der Kontrahenten, erlaubten Inhalt, Existenz der res etc. oder die acceptilatio, so erheischt sie

einerseits kongruierende Frage und Antwort, and erseits Handlungsfähigkeit der Kontrahenten, Bestand einer Stipulationsschuld, Unbedingtheit, Unbefristetheit etc.

oder endlich ein Delikt, so können wir unter seinen Tatbestandsmerkmalen auseinanderhalten:

einerseits den sog. objektiven Tatbestand, d.h. den äußerlich wahrnehmbaren Eingriff in fremde Rechtssphäre, anderseits den subjektiven Tatbestand, d. h. das Verschulden des Delinquenten.

Wer wollte leugnen, daß die in diesen Beispielen einander entgegengestellten Tatbestandsmerkmale einen verschiedenen Charakter tragen? Was liegt also näher für die Rechtsordnung, als bei Aufstellung ihrer Sätze dieser Verschiedenheit Rechnung zu tragen und in den Mittelpunkt diejenigen Tatbestandsmerkmale zu stellen, welche der äußeren Wahrnehmung allgemein zugänglich sind? oder anders ausgedrückt: diese Merkmale zum Ausgangspunkt zu nehmen für die Anknüpfung bestimmter Rechtswirkungen selbst auf die Gefahr hin, hiermit von den Anforderungen strenger Logik in etwas abzuweichen? Gewinnt sie doch so die Möglichkeit, scharf abgegrenzte Tatbestände, Tatbestandstypen in einfacher Weise aufzustellen. ${ }^{1}$ ) Wenn sie nun in dieser Weise verfährt, so ist es nur die Kehrseite des Ver-

1) Bechmann, Kauf II S.13. 
fahrens, zu unterscheiden, ob die sonstigen Voraussetzungen der Rechtswirkungen sich um den äußerlich erkennbaren Tatbestand im konkreten Falle gruppiert finden oder nicht und den ersten Fall als den Normalfall zu betrachten, letzterenfalls aber zu bestimmen, daB die Wirkungen nicht eintreten, die sich sonst an den Tatbestand anknüpfen müßten, weil der letztere nicht von allen zu seiner Wirksamkeit erforderlichen Voraussetzungen umgeben ist. Auch bei den nach Naturgesetzen sich vollziehenden Wirkungen findet sich ein ähnlicher Sprachgebrauch in Fällen, wo die Wirkung teils von äußerlich erkennbaren, teils von verborgenen Ursachen abhängt. Das Öffnen des Auges bezeichnen wir als den Tatbestand, welcher das Erblicken der Außenwelt zur Folge hat. Es ist aber klar, daß diese Folge weiter bedingt ist von der Ungestörtheit der Funktionen des Sehnervs. Fehlt die letztere im konkreten Falle, so fällt es niemandem ein, zu leugnen, daß der Augenaufschlag erfolgt sei, sondern es wird für diesen Fall dem Augenaufschlag die übliche Folge abgesprochen, weil es an den Umständen gebricht, unter denen gewöhnlich diese Bewegung erfolgt. Und wenn es auch zuträfe, daß man auf dem Gebiete des Strafrechts nicht von straflosen und strafbaren Verbrechen spricht, ${ }^{1}$ ) so ist es doch nicht zu bestreiten, daß man den straflosen objektiven Tatbestand mit derselben Bezeichnung belegt, welche der Straftat zukommt. Niemand wird Bedenken tragen, von einem "Totschlag" in Notwehr, von der "Sachbeschädigung" oder "Körperverletzung" seitens eines Geisteskranken oder eines Kindes zu sprechen. Übrigens scheut sich die Sprache des Gesetzes nicht, in Fällen, wo durch die Tat ein Strafrecht des Staates ausnahmsweise nicht begründet wird, von "strafbarer" Handlung zu reden. Vgl. RStGB. §§ 55. 56. 59. 194. 232.

Für die Wissenschaft des römischen Rechts ist nun zuzusehen, wie die Quellen selbst sich verhalten. Da ergibt sich denn aus dem hier beigebrachten Material der unabweisbare Schlul, daß die Römer genau so verfuhren, wie es vorhin als sehr naheliegend erklärt wurde. Sie legen

1) Schloßmann a. a. O. S. 17 Nr. 25. 
in der Tat das Gewicht auf die in die Sinne fallende Erscheinung des Tatbestandes, wo sie über den Eintritt oder das Ausbleiben von Rechtswirkungen urteilen.

Man vergleiche $1.11 \S 7$ D. 24. 1 im Gegensatze zu 1. 11 \$ 9 eod., von welchen Stellen die erste sagt: traditio ... egit aliquid, die letztere: nihil agitur ea traditione? Es ist unverkennbar, daß als das agens dort die traditio angesehen und daß hier der traditio der Charakter eines agens abgesprochen wird.

1. $57 \S 1$ D. 18.1. Si autem venditor quidem sciebat domum esse exustam, emptor autem ignorabat, nullam (M: nullo $\operatorname{modo}$ ) venditionem stare, si tota domus ante venditionem exusta sit: si vero quantacunque pars aedificii remaneat, et stare venditionem et venditorem emtori quod interest restituere.

Was äußerlich sichtbar wird, ist hier die venditio; von ihr wird in dem einen Fall ausgesagt: nullo modo stare, im andern stare venditionem. In beiden Fällen wird sohin das Urteil des Rechts abgestellt auf den Tatbestand venditio, der in beiden von verschiedenen, eine Veränderung in der Außenwelt nicht hervorrufenden Umständen begleitet ist, dem totam domum esse exustam im einen, dem remanere aliquam partem aedificii im anderen.

1. $8 \S 5$ D. 30 . Si ei servo, qui testamento legatum acceperit, libertas codicillis datur, utile legatum esse dicemus, quasi ab initio constiterit legatum. Der Tatbestand, von welchem ausgesagt wird, daß er ein utile legatum sei, ist das legare testamento. Doch soll diese Utilität bedingt sein durch das dare libertatem codicillis. Vorher legatum non constitit; denn erst nachher wird es behandelt, quasi ab initio constiterit. Die Wirkung, welche eintritt, wird mithin angeknüpft an die äußere Erscheinung des legare, vorausgesetzt, daß der legatarius servus mit dem Tode des Erblassers frei wird; andernfalls hat jener Tatbestand die ihm sonst beigelegte Wirkung nicht.

1. 19 i. f. D. 37.4 (oben Bd. XXIII S. 406 C.1) versagt den tabulae testamenti den effectus, den sie gehabt hätten, wenn die Eingesetzten den Erblasser überlebt bezw. wenn sie testamentifactio passiva besessen hätten. 
l. 12 p. D. 23.3 (s. o. S. 406 Nr. 3). Donatio ist da; allein während sie sonst Wirkungen äußert, bleibt sie, d. h. der äußerlich wahrnehmbare Tatbestand des Schenkens, unter Eheleuten ohne Wirkung.

l. $46 \S 7$ D. 49.14 (o. S. 406 Nr. 4). Von venditio heißt es hier, dah sie nullas vires habet aus dem in der Stelle angegebenen Grunde. Würde dieser Grund nicht bestehen, so müßte die venditio demnach vires habere. Das Ding, von dem bald vires habet, bald vires non habet ausgesagt wird, bleibt also immer dasselbe, die venditio, d. i. der in Konsenserklärung über merx und pretium zur Erscheinung kommende Tatbestand.

1. 63 D. 23.2 (o. S. 407 Nr. 1). Das arg. e contrario zwingt zu dem Schluß: matrimonium erit, wenn nicht gegen ein Verbot das uxorem ducere erfolgt. uxorem ducere ist sonach der Tatbestand, dessen regelmäßige Wirkung (matrimonium) unter gewissen Umständen ausbleibt.

Gai. I. 147 (o. S. 409 Nr. 4). Danach ist die heredis institutio eines extraneus postumus zwar verpönt, aber sie bleibt institutio; verglichen mit der institutio postumi sui entbehrt sie freilich der Wirkung, die jene hat.

l. 29 \& 1 D. 29.1 (o. S. 410 Nr. 1). Die manumissio wird als wirkungslos erklärt für den besonderen Fall, daß ihrer (sonstigen) Wirkung, der libertas, die lex Aelia Sentia in den Weg tritt.

1. 7 D. 45.1 (o. S. 412 Nr. 12). Stipulatio ist auch vorhanden, wenn sie sub impossibili condicione erfolgt. ${ }^{1}$ ) Nur steht ihrer sonstigen Wirkung gerade die impossibilis condictio entgegen.

1. 77 D. 50.17 (o. S. 413 G. Nr. 1). Danach bedarf es erst eines Umstandes, der den actus legitimus fehlerhaft macht, wenn seine unter normalen Verhältnissen eintretende Wirkung ausgeschlossen sein soll. Actus legitimus aber ist der durch bestimmte Frklärungen in die Außenwelt tretende Akt der emancipatio, acceptilatio etc.

1. 51 (50) pr. D. 28.5 (o. S. 413 Nr. 2). Die heredis institutio servi, d. h. der im Testament zum Ausdrucke ge-

1) cf. Koschembahr-Lyskowski S. $115 \$ 9$. 
langte Erbeinsetzungswille, hat unter den in der Stelle angegebenen Voraussetzungen die Folge des heredem esse; mangelt es aber an einer dieser Voraussetzungen, so wird dieser Tatbestand fehlerhaft und die Wirkung bleibt aus.

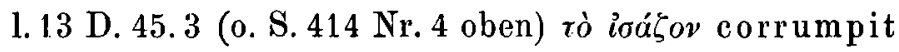
stipulationem drückt den Gedanken aus, daß die Rechtswirkung, welche der Regel nach an den äußeren Tatbestand der stipulatio sich anknüpft, fehlt, wenn dieser Tatbestand verdorben ist.

1. 49 (48) D. 28.5 (o. S. 414 Nr. 1). Unter den in der Stelle erwähnten Umständen ist der Sklave als non iure manumissus zu betrachten. Manumissus wird er trotzdem genannt, ein Beleg, daß sich der Jurist die Alternative eines iure und eines non iure manumitti vorstellt, unter dem letzteren aber einen Manumissionsakt denkt, dem die Wirkung abgeht, weil er von abnormalen Verhältnissen umgeben ist. Vgl. hierzu 1. $20 \$ 1$ D. 28. 7. Labeo 1. 2. posteriorum a Iavoleno epitomat.: $\mathrm{Si}$ quis hereditarium servum iussus est manumittere et heres esse, quamvis, si manumiserit, nihil agat, tamen heres erit: verum est enim, eum manumisisse ...

1. 19 D. 49.1 (o. S. 415 Nr. 9). Indem der sententia quae non iure profertur die Wirkung der Streitbeendigung abgesprochen wird, wird implizite anerkannt, daß der streitbeendigende Tatbestand die sententia prolata sei, also wiederum ein äuferlich erkennbarer Akt, dem die Wirkung nur wegen besonderer, nicht in die Sinne fallender Umstände abgeht.

1. 4 D. 26. 8. . si tutor a uctoretur, cui administratio tutelae concessa non est, id ratum a praetore haberi non debet... item si eo auctore emam quia tutela fuerit remotus: nec enim id ratum haberi.

Das auctorari des tutor ist es, was die Handlung des Pupillen und das Handeln mit dem Pupillen wirksam macht. Dieses auctorari ist aber unter Umständen als fehlerhaft der Wirkung entkleidet.

1. 4 C 7.11. Si minor viginti annis ad libertatem praestandam homines tradidisti, senatusconsulto quod gestum 
est irritum constituitur. Quod gestum est ist die traditio hominum. Geschieht sie nicht ad libertatem praestandam, so ist sie der Regel gemäb wirksam; irrita ist sie, i. e. der Traditionsakt aus dem besonderen Grunde, den die Stelle anführt.

1. 3 C. 2.21 (22) (o. S. $420 \mathrm{Nr} .2$ ). Die normale Wirkung jedes contractus besteht in dem Zwange zum servare contractum; diese Wirkung kann aber aus besonderen Gründen fehlen.

Vgl. den gleichen Standpunkt der $1.7 \S 16$ D. 2.14 für das pactum.

l. 30 D. 23. 2. Simulatae nuptiae nullius momenti sunt, d. h. Nuptiae, der erkennbare Tatbestand des nubere, ist zwar auch bei simulatio vorhanden; allein während dieser Tatbestand ohne Simulation rechtliche Bedeutung hat, entbehrt er dieselbe bei unterlaufender Simulation. Vgl. ferner sämtliche oben $\mathrm{S}$. 421/2 für nullius momenti esse angeführten Stellen.

Die gleiche Auffassung kehrt wieder für die Tatbestände, die als inutilia bezeichnet (o. S. 422/3) und für jene, die mit non valere prädiziert werden (o. S. 423/4). DaB sie die Verwendung von nullum esse und non esse ebenfalls beherrscht, folgt aus den obigen Ausführungen (S. 59 ff.) zur Genüge. Sie liegt aber auch den Wendungen pro nihilo esse, pro non facto haberi, inane esse und frustra facere $\mathrm{zu}$ grunde, wie die folgenden Beispiele zeigen mögen:

Weil der äußerlich erkennbare Tatbestand der conductio, d. h. die Konsenserklärung über merces und res utenda als der wirkende Tatbestand gedacht wird, deshalb wird beim Ausbleiben der Wirkungen quasi nulla mercede statuta von diesem Tatbestand gesagt: pro nihilo esse conductionem: 1. 25 p. D. 19.1, weil das iurare in iure, also etwas allgemein Wahrnehmbares, als die Ursache gewisser Wirkungen gedacht wird, deshalb wird das wirkungslose iurare angesehen, als wäre es kein iurare: 1. 33 D. 12.2. iurasse non videtur; weil die Tatsache des Kontrahierens als Ursache der Entstehung einer actio gilt, deshalb wird diese Tatsache inanis genannt, wo ausnahmsweise jene Wirkung ausbleibt: l. 11 D. 44. 7. inanem actum nostrum efficiunt; weil die Tat- 
sache der conventio als der Grund für die Obligierung erscheint, deshalb wird die conventio eine vergebliche genannt, wo sie eine Obligierung nicht zur Folge hat: 1.14 D. 17. 2; frustra hoc convenire.

Noch entschiedener kommt die erwähnte Betrachtungsweise zum Ausdrucke in der Wendung non posse fieri oder facere. Denn obwohl hier auf der Hand liegt, daß der äußere Tatbestand ohne alle Schwierigkeit hergestellt werden kann, wird diese Möglichkeit verneint, wo die Rechtswirkung fehlt. Doch wohl aus keinem andern Grunde, als weil mit der Annahme des äußeren Tatbestandes sich die Vorstellung seiner Rechtswirkung verbindet (s. die sämtlichen oben S. $416 / 9$ sub J. angeführten Stellen).

Auf die gewonnenen Ergebnisse läßt sich gewissermaßen die Probe machen, wenn die Fälle herangezogen werden, in welchen die Quellen aus besonderem Grunde sich veranlaßt sehen, die Wirksamkeit eines Tatbestandes hervorzuheben.

Adoptare possunt in $1.2 \$ 1$ D. 1.7 (o. S. $385 \mathrm{Nr} .1$ ); emancipare potest in l. 4 D. 1.7 (o. S. 387 Nr. 3); sponsalia non infirmat in 1.8 D. 23.1 (o. S. $388 \mathrm{Nr} .5$ ); traditio egit aliquid in I. 11 \$ 7 D. 24 (o. S. 390 d); nec tamen emptioni obstat in 1.16 \$ 1 D. 18.1 (o. S. 391 Nr. 4 b); recte enim negotium gerere intelligitur in $1.35 \S 3 \mathrm{D} .18 .1$ (o. $\mathrm{S} .391$ Nr. 4 c); emtio valet in $1.7 \$ 1$ D. 18.1 (o. S. $391 \mathrm{Nr} .4 \mathrm{~d}$ ); vires habere stipulationem in 1.38 \& 6 i. f. D. 45.1 (o. S. 392 Nr. 5d); transactio rata est in $1.8 \S 25$ D. 2.15 (o. S. 392 Nr. 6 b); donationem effectum habituram in $1.32 \S 23$ D. 24.1 (o. S. 393 Nr. 8 c); pactum servandum in 1.12 p. D. 23.4 (o. S. $395 \mathrm{Nr} .10 \mathrm{~g}$ ); non vitiare legatum in $1.6 \$ 1$ D. 33.8 (o. S. $396 \mathrm{Nr} .12 \mathrm{e}$ ); erit utilis ea institutio in $1.69(68)$ D. 28.5 (o. S. 397 Nr. 16 g).

Überall ist es ein sichtbarer Vorgang, welchem eine rechtliche Wirksamkeit zugeschrieben wird: wie die Förmlichkeit der Adoption und Emanzipation, die Erklärung des Verlöbniskonsenses, die Besitzübergabe, die Erklärung des Kaufkonsenses, die kongruente Frage und Antwort der Stipulation, die Erklärung und Annahme des Vergleichswillens, des Schenkungswillens, des duorum pluriumve in idem pla- 
citum consensus (= pactum), der Anordnung des Legats oder der Erbeinsetzung.

Nirgends wird auch nur angedeutet, dab die Wirksamkeit deshalb eintrete, weil außer dem sichtbaren Vorgange auch noch andere allgemeine Voraussetzungen der Wirksamkeit vorliegen. Vielmehr wird die Wirksamkeit eben des sichtbaren Vorgangs bekräftigt, um Zweifel auszuschließen, welche aus der besonderen Umgebung desselben abgeleitet werden könnten.

Dem entgegen versucht man von anderer Seite ${ }^{1}$ ) gerade die Sprache der Quellen dafür anzurufen, „daß auch sie ein Rechtsgeschäft im Rechtssinne nur dann als vorhanden annehmen, wenn der gesamte Tatbestand, welcher die juristische Voraussetzung einer Rechtswirkung bildet, vorliegt; unter dieser Voraussetzung allein hielten sie den Gebrauch der technischen Bezeichnung des Geschäfts für zulässig, jeden anderen Gebrauch derselben für mißbräuchlich."

Das soll insbesondere hervorgehen aus folgenden Stellen:

1. $1.2 \S 1$ D. 29.3 (o. S. 67). Allein diese Stelle ist weit entfernt davon, den Gebrauch des Wortes testamentum überall da mißbräuchlich zu nennen, wo nicht alle Voraussetzungen der Rechtswirkung vorliegen. Vielmehr bringt dieselbe das iure perfectum testamentum in Gegensatz:

a) zum testamentum falsum, d. i. dem unechten Testament, also der gar nicht vom Erblasser ausgegangenen Verfügung,

b) zum testamentum iniustum, d. i. nach 1.1 D. 28.3 zu demjenigen letzten Willen, welchem die solemnia iuris fehlen,

c) zum testamentum irritum, d. i. jenem, welches non adita hereditate der Wirkung entbehrt,

d) zum testamentum ruptum, d. i. dem Testament, das der Wirkung beraubt wird durch ein zweites Testament oder durch agnatio postumi,

e) zum testamentum imperfectum, d. i. demjenigen, welchem die deutliche Bezeichnung des begünstigten Subjekts fehlt (o. S. 68).

1) Schloßmann a. a. O. S. $16 \mathrm{f}$.

Zeitschrift für Rechtsgeschichte. XXIV. Rom. Abt. 
$\mathrm{Da}$ ein mißbräuchlicher Sprachgebrauch vorliege, wenn testamentum gesagt wird von der Erbeinsetzung seitens eines filius familias, prodigus, furiosus oder von der Person, welche testamenti factio passiva nicht besitzt oder welche in arbitrium tertii verstellt ist, bleibt dahingestellt.

Übrigens nimmt Ulpian keinen Anstand, sich selbst mit den andern der mißbräuchlichen Verwendung des Wortes testamentum zu zeihen (appellamus), woraus folgt, daß man an dem abusus keinen Anstand nahm.

2. 1. 24 D. 40.7: .. nam spopondisse (scil. servus) aliqua significatione dici potest, etiamsi non sit secuta obligatio. Hier wird der Gebrauch von spondere für den Sklaven durchaus nicht für mißbräuchlich erklärt, sondern gerade im Gegenteil gerechtfertigt. Es wird angedeutet, daß man regelmäßig eine obligatio im Gefolge des spondere denkt, daß man aber doch in einem gewissen Sinne von spondere auch reden könne, wenn obligatio non secuta est.

3. 1. 4 \& 6 D. 42.1 . Condemnatum accipere debemus eum, qui rite condemnatus est, ut sententia valeat: ceterum si aliqua ratione sententia nullius momenti sit, dicendum est, condemnationis verbum non tenere. Die letzten Worte sagen nicht, daß von condemnatio mißbräuchlich gesprochen werde, sondern daß das Wort der condemnatio (nicht: das Wort condemnatio) keine Verbindlichkeit habe (tenere), wenn die sententia nullius momenti sei, d. h. obwohl der Richter ausgesprochen hat: Condemno $\mathrm{N}^{\mathrm{m}} \mathrm{N}^{\mathrm{m}}$, bindet das den N. N. doch nicht. Als mit Wirksamkeit kondemniert kann daher freilich nur der rite condemnatus erachtet werden.

4. 1. 1 2 D. 2. 2. Haec autem verba: 'quod statuerit qui iurisdictioni praeest' cum effectu accipimus, non verbo tenus: et ideo si, cum vellet statuere, prohibitus sit nec effectum decretum habuit, cessat edictum. nam statuit verbum rem perfectam significat et consummatam iniuriam, non coeptam. et ideo si inter eos quis dixerit ius, inter quos iurisdictionem non habuit, quoniam pro nullo hoc habetur nec est ulla sententia, cessare edictum putamus: quid enim offuit conatus, cum iniuria nullum habuerit effectum?

Diese Stelle handelt ron dem Edikte: Quod quisque iuris in alterum statuerit, ut ipse eodem iure utatur und 
hebt in ihrem Anfange geradezu hervor, daB die wörtliche Bedeutung von statuere den sichtbaren Akt des magistratischen Dekretes bezeichne. Im Sinne seines Ediktes wolle aber der Prätor von dem Wortsinne abweichen und unter statuere verstehen: cum effectu statuere. Demgegenüber bedeuten die letzten Worte der Stelle nicht, daß sententia von dem Spruch eines durch den inkompetenten Prätor bestellten iudex gesagt, ein Mißbrauch des Wortes, sondern $\mathrm{da} ß$ diese sententia wirkungslos sei.

Man mag nun in all den Fällen, wo dem sichtbaren Tatbestande aus gewissen Gründen die Wirkung abgeht, sofern dieser Tatbestand in einer Willenserklärung besteht, ihm die Eigenschaft eines "Rechtsgeschäfts" im Sinne moderner Terminologie absprechen, eine Konsequenz aus der römischen Sprechweise ist das nicht; denn es bleibt die Wahrnehmung bestehen, da $\beta$ in solchem Falle doch der Tatbestand vorliegt, welchen die Römer der Regel nach als die Voraussetzung von gewissen Rechtswirkungen ansehen und den sie nur aus besonderen Gründen der Auslösung solcher Wirkungen für unfähig halten. ${ }^{1}$ )

Auch Karlowa ${ }^{2}$ ) verwirft die Bezeichnung "nichtig“ als Prädikat des Rechtsgeschäfts, einmal, weil es zweifelhaft erscheine, ob der Begriff der Nichtigkeit als Unfähigkeit zur Erzeugung der normalen Wirkungen, auf Rechtsgeschäfte beschränkt werden dürfe und nicht vielmehr auf alle iuristischen Tatsachen ausgedehnt werden müsse; sodann, weil, wie schon Unger ${ }^{3}$ ) hervorgehoben habe, die Folge mit dem Grunde verwechselt werde.

Wollte man den Nichtigkeitsbegriff auf alle juristischen Tatbestände anwenden, so verlöre er allen Wert. Denn dann gäbe es eben nur gewisse Tatsachenkomplexe von rechtlicher Wirkung; fehle auch nur eine zugehörige Tatsache, so bleibe auch die Rechtswirkung aus.

Die Verwechselung von Grund und Folge liege aber zu Tage, da ein Rechtsgeschäft wirkungslos sei wegen seiner Nichtigkeit und nicht umgekehrt. Man müsse daher

1) Vgl. auch Brodmann, Der Stoff des Rechts S. 110. Danz, Die Auslegung der Rechtsgeschäfte S. 35 ff. 40. - $\left.{ }^{2}\right)$ Das Rechtsgeschäft, S. 117. $-{ }^{3}$ ) System des österr. allg. Privatrechts II $§ 91$. 
die herkömmliche Definition des Rechtsgeschäftes aufgeben und dasselbe als etwas von seinem Errichtungsakt Verschiedenes bestimmen, als "die durch den Errichtungswillen infolge der Anerkennung seitens der Rechtsordnung bewirkte Fessel und Gebundenheit der Parteien bezüglich des Eintritts der ins Auge gefaßten Rechtswirkung". Trete diese Gebundenheit wegen eines Mangels der Errichtung nicht ein, so sei überhaupt kein Rechtsgeschäft zur Existenz gekommen, negotium nullum. Der Begriff nichtig $=$ wirkungslos sei daher nicht auf das Geschäft, sondern auf den Errichtungswillen anzuwenden.

Das erste Bedenken Karlowas besteht für uns aus den bereits angeführten Gründen nicht.

Wenn es wahr ist, daß die Römer an Tatbestandstypen, aus erkennbaren Tatsachenkomplexen bestehend, die Rechtswirkung angeknüpft gedacht haben, so hat der Nichtigkeitsbegriff für jeden juristischen Tatbestand die Bedeutung, daß seine Wirkungsfähigkeit fehlt, falls gewisse anderweitige Umstände bestehen, deren Vorhandensein diese Fähigkeit ausschließt. Verwechslung von Grund und Folge kann aber gewiß demjenigen nicht zum Vorwurf gemacht werden, dem Wirkungsunfähigkeit gar nicht Ursache der Nichtigkeit, sondern mit Nichtigkeit synonym ist. $\left.{ }^{1}\right)$ Eben deshalb nötigt auch nichts zur Bezeichnung des Errichtungswillens als nichtig, wo es sich um sogenannte Rechtsgeschäfte handelt, sobald man nicht den Rechtsgeschäftsbegriff Karlowas acceptiert. Täte man freilich dies, d. h. verstünde man unter Rechtsgeschäft „die durch den Errichtungswillen bewirkte Fessel und Gebundenheit der Parteien", so könnte man allerdings nicht von dem Vorhandensein eines Rechtsgeschäfts sprechen, wo diese Gebundenheit nicht bewirkt ist; denn das hieße sich eine "nicht bewirkte Gebundenheit" vorstellen.

Karlowa sucht auch darzulegen, daß der schroffe Gegensatz zwischen dem rechtlich existenten Geschäfte und dem negotium nullum die tatsächlichen Erscheinungen der Quellen keineswegs erschöpfe. Unter Berufung auf Kretschmar ${ }^{2}$ )

1) Vgl. auch Zitelmann, Irrthum S. 298/9. - 2) Die Natur des. Prälegats S. 211-215. 
unterstellt er den römischen Juristen eine Distinktion zwischen letztwilligen Verfügungen, welche non data und solchen, welche inutiliter data sind, und geht über Kretschmar hinaus, indem er diese Unterscheidung verallgemeinert wissen will.

Während aber Kretschmar inutiliter datum das aus einem Rechtsgrunde und trotz des Willens des Testators Ungültige nennt, non datum das vom Erblasser nicht oder nicht vollständig oder bei Kenntnis der Sachlage vermutlich nicht Gewollte und deshalb Ungültige, stellt Karlowa die angebliche Unterscheidung darauf $a b$, daß non datum oder nullum negotium im strengsten Sinne das Geschäft sei, bei welchem es an den notwendigen Voraussetzungen des Errichtungswillens fehle, inutiliter datum jenes, wo diese Voraussetzungen erfüllt sind, jedoch aus einem andern Grunde die gewollte Rechtswirkung ausbleibe. Wo es nicht am Errichtungswillen fehle, da könne das Geschäft auch, wenn schon nicht die beabsichtigte, so doch eine andere Wirkung hervorbringen. ${ }^{1}$ )

Das letztere soll sich insbesondere aus Gaius III. 176. 179 ergeben, wonach die Novationspromission eines Pupillen oder einer mulier sine tutoris auctoritate zwar keine obligatio erzeugt, aber doch die bestehende obligatio aufhebt, während auch dies nicht der Fall sei bei Promission seitens eines Sklaven. Bei diesem fehle es nämlich an dem erforderlichen, rechtlich anerkannten Errichtungswillen, der bei mulier und pupillus gegeben sei.

Dementgegen möchte ich annehmen, es erkläre sich die Novationswirkung bei Promission des Pupillen und der mulier aus der Tatsache genügend, daß hierdurch eine naturalis obligatio begründet wurde (vgl. Gai. III. 119 u. § 3 J. $3.29(30)$ ) und daß daher von posterior stipulatio inutilis oder nulla gesprochen wird nur, weil keine actio entsteht.

Dagegen wendet freilich Salpius ${ }^{1}$ ) ein nicht blok, daß es bei promissio servi anders gehalten werde, obgleich doch auch sie eine naturalis obligatio erzeuge, sondern auch, dak die Annahme falsch sei, wonach das Minimum der Novationserfordernisse in der Begründung einer obligatio naturalis bestehe. Vielmehr müsse man in $1.1 \S 1$ D. 46.2 die Worte:

1) Karlowa a. a. O. S. $\left.120 .-{ }^{2}\right)$ Novation S. 149. 150. 
dummodo sequens obligatio aut civiliter teneat, aut naturaliter streng disjunktiv verstehen, d. h. man müsse darin ausgesprochen finden: entweder ist eine formell giltige civilis obligatio notwendig, gleichviel ob ihre Wirksamkeit durch exceptio völlig, nämlich auch in ihrem naturalen Bestandteil, zerstört ist, oder eine naturalis obligatio.

Allein daraus folgt doch nicht, daß Novation nicht eintrete, wenn eine naturalis obligatio begründet wird.

Es bleibt daher nur die eine Schwierigkeit, daß die promissio servi nicht zur Novation führt.

Dafür gibt aber Karlowa selbst, wie mir scheint, eine ausreichende Erklärung. ${ }^{1}$ )

Abgesehen von alledem wäre es doch auch eine seltsame Laune der Rechtsordnung, wenn sie einerseits das Gewicht auf den Errichtungswillen legen und anderseits bei dessen Vorhandensein gerade nicht gewollte Wirkungen eintreten ließe, wo die gewollten wegen anderer Mängel des Geschäfts nicht eintreten können.

Übrigens läßt sich die Unhaltbarkeit der Behauptung, daß die Quellen zwischen non datum oder nullum und inutiliter datum unterscheiden, vollständig widerlegen.

Karlowa rechnet die Beobachtung der vorgeschriebenen Form des Geschäfts zu den Erfordernissen des Errichtungswillens und nimmt nullum negotium an, wo es an dieser Form fehlt.

Trotzdem sagt uns Gaius II. 229 De inutiliter relictis legatis: Ante heredis institutionem inutiliter legatur... cf. $\S 34$ J. 2.20.

In 1. 65 D. 35.2 wird ein Legat von 50 aurei unter der Bedingung, daß der Legatar 50 aurei dem Erben geben würde inutile und magis ridiculum genannt, während man wegen Mangels jedes Errichtungswillens nullum legatum erwarten müßte, wenn jene Unterscheidung gemacht würde. Desgleichen ist es nach $1.34 \S 2$ D. 40.5 inutiliter legatum, wenn ein Sklave mit der Auflage der Freilassung dem Calpurnius Flaccus, bei Nichterfüllung der Auflage dem Titius vermacht und für den Fall auch Titius ihn nicht freiließe, dem Sklaven die Freiheit vermacht wurde.

1) S. 119 Z. 4 ff. v. o. 
Endlich wird in 1. 6 p. D. 48.10 ein legatum contra SC Libonianum als inutile bezeichnet, obgleich doch die Inutilität auf der Annahme der Fälschung, also des mangelnden Errichtungswillens beruht.

Den Mangel der testamenti factio in der Person des Vermächtnisnehmer's rechnet Karlowa ${ }^{1}$ ) ebenfalls zu den Voraussetzungen des Errichtungswillens, und folglich ist ihm das legatum zu gunsten eines Unfähigen non datum, nicht inutile.

Aber Gaius III. 238. 241 berichtet, daß incertae personae inutiliter relinquitur und postumo alieno inutiliter legatur. Vgl. $\S 824-26$ J. 2. 20.

Andere Stellen zeigen uns den synonymen Gebrauch von nullum und inutile, so $1.82 \S 2$ i. f. D. 31 und 1.29 D. $23.3 ; 1.82 \S 5$ D. 30 und $1.75 \S 1$ D. eod. für Legate, l. 9 \$ 6 D. 12.1 und $\S 11$ J. 3.19 für Stipulationen, 1.54 p. D. 17.1 und 1.1 C. 4.36 für das Mandat.

Die besprochenen Bedenken dürften nach alledem nicht geeignet sein, die Berechtigung des Sprachgebrauches: „nichtiger juristischer Tatbestand", "nichtiges Rechtsgeschäft" vom Standpunkte der römischen Quellen aus zu erschüttern.

Die Quellen zeigen uns aber auch krankhafte Tatbestände (Rechtsgeschäfte), welche zwar die normale Wirkung nicht schlechthin entbehren, aber derselben nicht in dem Grade teilhaftig sind, welcher in Ermanglung jeder pathologischen Erscheinung dem Tatbestande entsprechen würde. Man hat sich gewöhnt, Tatbestände dieser Art, soweit sie unter den Rechtsgeschäftsbegriff gestellt werden, „anfechtbar" zu nennen.

Wir wenden uns im Folgenden zunächst der Feststellung des Verhältnisses $z u$, in welchem die Sprache der Quellen zu den Fällen dieser Art steht.

\section{V.}

Bisweilen findet sich von einem Tatbestande ausgesagt, daß eine retractatio desselben zulässig sei.

So in $1.32 \S 14$ D. 4. 8. Paul. 1.13 ad edict.: Cum quidam arbiter ex aliis causis inimicus manifeste apparuisset,

1) a. a. O. S. 128 . 
testationibus etiam conventus ne sententiam diceret, nihilo minus nullo cogente dicere perserverasset, libello cuiusdam id querentis imperator Antoninus subscribsit posse eum uti doli mali exceptione. et idem cum a iudice consuleretur, apud quem poena petebatur, rescripsit, etiamsi appellari non potest, doli mali exceptionem in poenae petitione obstaturam. per hanc ergo exceptionem quaedam appellandi species est, cum liceat retractare de sententia arbitri.

Die sententia arbitri ist bestimmt, das Rechtsverhältnis unter den Parteien endgiltig zu regeln, mag sie inhaltlich zutreffend sein oder nicht. Von einer Appellation kann keine Rede sein. Das ist die Regel. Leidet aber der Schiedsspruch an dem begründeten Verdachte der Parteilichkeit, so soll derjenige, der behauptet, daß sie gegen ihn sich richte, in die Lage versetzt werden, eine andere Instanz gegen den Schiedsspruch anzurufen, indem er sich Folge zu leisten weigert, es auf die Klage ex compromisso ankommen läßt und dieser die Behauptung der Parteilichkeit entgegensetzt. Der Richter hat alsdann diese Behauptung auf ihre Wahrheit zu prüfen, und wenn er sie begründet findet, den Beklagten zu absolvieren. Dadurch wird die sententia arbitri ihrer Rechtswirkung entkleidet.

Auf jeden Fall wird dem Beklagten die Möglichkeit eröffnet, die Kraft des Schiedsspruchs von einer erneuten richterlichen Prüfung seines Inhalts abhängig zu machen.

Es läßt sich nicht sagen, daß der Schiedsspruch der Rechtswirkung ganz entbehre. Denn die Weigerung seiner Erfüllung ist die Bedingung der Klage aus dem Kompromil. Allein während sonst keine Instanz über seinen Inhalt angerufen werden kann, ist dies ausnahmsweise bei inimicitiae manifestae möglich.

Diese Möglichkeit ist nach Inhalt der obigen Stelle nicht etwa so zu denken, als ob die Tatsache der inimicitiae manifestae schon mit Notwendigkeit die Absolvierung des Beklagten begründe; sonst könnte wohl nicht gesagt werden 'quaedam appellandi species' est. Vielmehr weist diese Wendung darauf hin, daß der Richter die inhaltliche Richtigkeit des Spruches zu prüfen habe. Diese Prüfung könnte auch zur Kondemnation des Beklagten führen. Die endgültige 
Bedeutung des Schiedsspruchs war aber auch dann zum Wanken gebracht worden.

Wie in 1.32 \& 14 cit. in Verbindung mit dem Schiedsspruch, so findet sich retractare in einer Reihe anderer Stellen in Verbindung mit dem staatsrichterlichen Urteil:

1. 24 D. 4. 3. Ulp. 1. 11 ad edictum. Si dolo acciderit eius qui verba faciebat pro eo qui de libertate contendebat, quominus praesente adversario secundum libertatem pronuntietur, puto statim de dolo dandam in eum actionem, quia semel pro libertate dietam sententiam retractari non oportet.

Sententiam retractare deutet auf eine Tätigkeit des absens adversarius. Denn ohne solche ist nicht einzusehen, wie das Gericht zur wiederholten Untersuchung des Falles gelangen konnte. $\mathrm{Ob}$ nun damit das unten zu erwähnende justinianische Rechtsmittel der retractatio gemeint sei oder einfach eine neue Klage des adversarius mit der Behauptung, daß die Kontumazialsentenz rechtswidrig erlassen war, kann dahingestellt bleiben. Denn in beiden Fällen handelt es sich um einen Parteiangriff auf ein Urteil, welches ohne denselben Rechtswirkungen zu äußern imstande ist.

Diese Bedeutung kommt dem Ausdruck retractare ferner $\mathrm{zu}$ in

1. $2 \S 2$ D. 40.16. Ulp. 1. 2 de off. consulis: Sicubi plane aetas eius, cuius retractatur conlusio, differendam retractationem in tempus pubertatis vel ulterius etiam (M) suadeat, quinquennium non currere dicendum est. \& 3 Quinquennium autem non ad perficiendam retractationem, sed ad inchoandam puto praefinitum.

1. 5 pr. D. eod. Hermogenian 1. 5. iuris epitom. Sententiam pro ingenuitate dictam collusionis praetextu semel retractare permittitur.

1. $29 \S 1$ D. 40.12. Arrius Menander 1.1 de re militari: Qui ingenuus pronuntiatus est, si se militiae dedit, intra quinquennium retractata sententia antiquo (M) reddendus est.

In all diesen Stellen handelt es sich um den Angriff auf ein Urteil, welches im Ingenuitätsprozeß pro ingenuitate 
erlassen worden war und zwar auf Grund einer Kollusion unter den Prozeßparteien. Ein solches Urteil erzeugt die Wirkung, daß dadurch der status ingenuitatis eines Freigelassenen festgestellt wird und festgestellt bleibt, wenn nicht rechtzeitig die Reaktion dagegen erfolgt. Erfolgt sie, so kann das Urteil aufgehoben werden, während diese Möglichkeit für ein nicht auf Kollusion beruhendes Urteil pro ingenuitate nicht besteht.

Man vergl. noch: 1.1 \$ D. 40.15. Marcian l. singul. de delatoribus: Sed interdum et intra quinquennium non licet de statu defuncti dicere: nam oratione divi Marci cavetur, ut, si quis ingenuus pronuntiatus fuerit, liceat ingenuitatis sententiam retractare, sed vivo eo qui ingenuus pronuntiatus est, non etiam post mortem, in tantum, ut etiam, si coepta fuit quaestio retractationis, morte eius extinguatur, ut eadem oratione cavetur.

In ähnlichem Sinne bezeichnet Paulus sent. V. 33, 1 die Appellation gegen ein erstinstanzielles Urteil als ein Mittel retractandae et revocandae sententiae, und im justinianischen Rechte findet sich unter dem technischen Namen retractatio ein nicht devolutives Rechtsmittel gegen die Urteile der Präfekten ausgebildet. Vgl. Bethmann-Hollweg III. S. 340.

Von einem richterlichen Urteil läßt sich, wenn es überhaupt rechtlich als existent in Betracht kommt, nicht sagen, $\mathrm{da}$ b es deshalb unwirksam sei, weil seine Aufhebung infolge eines Rechtsmittels noch möglich ist. Es ordnet das Rechtsverhältnis unter den Parteien wenigstens in bedingter Weise, d. h. für den Fall, daß es durch Rechtsmittel nicht angegriffen wird. Diese dem Urteil innewohnende Kraft wird aber zerstört, wenn ein Rechtsmittel erhoben worden ist. Und gerade diese Zerstörung wird in den Quellen als retractatio bezeichnet.

Aber auf richterliche Urteile beschränkt sich diese Verwendung von retractatio in den Quellen nicht.

So findet sich in 1.13 C. 1. 18. Leo et Anthemius a. 472: $\mathrm{Ne}$ passim liceat mulieribus suos contractus retractare in his quae praetermiserint vel ignoraverint ....

in 1. 42 C. 2.4. Leo et Anthemius a. 472: Si ex falsis instrumentis transactiones vel pactiones initae fuerint, 
quamvis iusiurandum his interpositum sit, etiam civiliter falso revelato eas retractari praecipimus .....

in 1.4 C. 7.26. Alexander: Venditioni ancillae consensum dedisse diversam partem si probaveris retractando contractum, quem ipsa ratum habuit, non audietur....

in 1. 6 C. 2.51. Valerian et Gallienus: ... poteris adito praeside provinciae in integrum restitutionem impetrare retractataque venditione recipies possessiones.

in $1.1 \$ 3$ C. 8.55 (56). Philippus a. $249: \ldots$ neque enim fas est ullo modo inquietari donationes, quas is qui donaverat in diem vitae suae non retractavit.

in 1. 31 C. 3. 28. Iustinian a. 528: Quae nuper ad testamenta conservanda nec facile retractanda sanximus (1. 30 C. eod.), ut ratione legis Falcidiae minime illis personis derelicta, quae ad inofficiosi testamenti querellam ex prioribus vocabantur legibus, non periclitentur testamenta, sed quod deest legitimae portioni .... tantum repleatur... etiam ad testamenta sine scriptis facienda locum habere sancimus.

1. $7 \S 6$ D. 24.1 ... cuius rescripti verba ideo rettuli, ut appareat venditionem inter virum et uxorem bona fide gestam non retractari.

Überall bezeichnet in diesen Gesetzesstellen retractare eine Tätigkeit, welche auf Beseitigung bereits eingetretener Rechtswirkungen abzielt bezw. diese Beseitigung herbeiführt.

In 1.42 C. 2.4 , 1. 6 C. 2.51 , 1. 31 C. 3.28 wird retractare zunächst auf die richterliche Handlung bezogen, welche die Beseitigung der eingetretenen Wirkungen eines Tatbestandes herbeiführt, jedoch unter der selbstverständlichen Voraussetzung, daß ein Beteiligter die richterliche Tätigkeit zu diesem Zwecke in Anspruch genommen hat. Das ergibt sich besonders deutlich aus I. 31 C. 3.28 , woselbst die Erhebung der querella inofficiosi als Voraussetzung der retractanda testamenta gedacht wird.

In 1.13 C. $1.18,1.4$ C. 7.26 , l. 1 \& 3 C. 8.55 und 1.7 § 6 D. 24.1 wird retractare direkt auf die Parteihandlung bezogen und wenigstens in $1.1 \$ 3 \mathrm{C}$. cit. mit revocare gleichbedeutend gebraucht (cf. Vat. fr. $\S 272$ i. f.). 
Hierher darf wohl auch gerechnet werden

l. $13 \S 1$ D. 44. 3. Hermogenianus 1. 6. iuris epitom. Reipublicae rationes subscriptae et expunctae adversus eum qui administravit, ultra viginti, adversus heredem vero ultra decem annos retractari non possunt.

Demnach ist es innerhalb bestimmter Frist nach der Rechnungsablage eines städtischen Verwaltungsbeamten zulässig, die bereits als richtig anerkannte Rechnung (wegen irriger Voraussetzungen bei der Anerkennung) zum neuerlichen Gegenstand der Erörterung zu machen, d. h. die erfolgte Anerkennung zu widerrufen und hierdurch die bisher vorhandene, den Rechnungsbeamten nach Maßgabe der Rechnung verpflichtende bezw. befreiende Wirkung zu beseitigen.

Auf Beseitigung einer eingetretenen Wirkung muß wohl auch bezogen werden

Paulus sent. V. 5 a, 11. Ratio calculi saepius se patitur supputari atque ideo potest quocumque tempore retractari, si non longo tempore evanescat.

Die Berechnung der Urteilssumme hat ohne Zweifel eine Wirkung. Das Urteil kann auf dieselbe vollstreckt werden. Allein diese Wirkung unterliegt der Aufhebung durch Korrektur der falschen Rechnung, welche intra longum tempus erfolgen darf. Von der Korrektur eines Rechnungsfehlers im Urteil muß die Stelle verstanden werden im Hinblick auf die Rubrik des Titel $5^{\text {a }}$ : 'de effectu sententiar um et finibus litium. ${ }^{11}$ )

Auf die das Vorhandene beseitigende Tätigkeit deutet retractare auch in Coll. 15. 3, 2, wo eine Konstitution von Diocletian und Maximian gegen die Manichäer ausspricht: maximi enim criminis est retractare quae semel ab antiquis statuta et definita suum statum et cursum tenent ac possident.

Wenn in 1.12 \$ D. 46.8 Ulp. 1.80 ad edictum die Verwirkung der stipulatio de rato angenommen wird, qualiter-

1) Über eine andere Möglichkeit s. Savigny, System, Bd. VI S. 381 N. o. Bethmann-Hollweg a. a. O. II $\$ 111$ N. 7 rerweist bez. dieser Stelle des Paulus auf $\$ 118$; dort findet sich jedoch hierüber nichts. 
qualiter quis eundem actum retractet, qui a procuratore actus est, so wird auch hier von der Voraussetzung ausgegangen, daß durch den actus procuratoris bereits gewisse Wirkungen eingetreten sind, um deren Rückgängigmachung durch den dominus es sich handelt. Vgl. ferner l. $3 \quad \& 1$ C. 5.74, wo es von der Veräußerung von Mündelgut heißt: post quinquennium minime retractari, sed tenere. Retractari wäre die Wiederaufhebung der Wirkung, die durch den Ablauf des quinquennium nach der Volljährigkeit eingetreten ist.

Auch in $1.1 \S 4$ D. 40.15 Marcian 1. singul. de delatoribus liegt die gleiche Bedeutung von retractare zu grunde. Denn 'retractare statum' nach dem Tode ist zwar wörtlich genommen die Erörterung über den status, den der Verstorbene innehatte, der Zweck solcher Erörternng geht aber auf die Beseitigung der Wirkungen, welche der status defuncti bei seinen Lebzeiten und bei seinem Tode hervorgebracht hatte.

Unter den Fällen, in welchen von retractatio und retractare die Rede ist, befindet sich eine Anzahl, wo die retractatio in der angegebenen Bedeutung des Wortes für zulässig erklärt wird; aus diesen lassen sich wiederum ausscheiden diejenigen, bei welchen die retractatio als eine normale Erscheinung auftritt und jene, wo die retractatio sich als die Folge einer Mangelhaftigkeit des Tatbestandes darstellt. Zu den ersteren gehört die retractatio eines Urteils durch Appellation (Paul. sent. V. 33. 1), dann die retractatio als nicht devolutives Rechtsmittel gegen Urteile der Präfekten (o. S. 90), die retractatio dessen, was ein unbevollmächtigter procurator namens des dominus negotii getan hat und die retractatio betr. des status defuncti; zu den letzteren die retractatio des Schiedsspruchs wegen manifestae inimicitiae, des Urteils pro ingenuitate wegen collusio, des Urteils wegen error calculi, der transactio wegen Urkundenfälschung (1. 42 C. 2.4), des Pfandverkaufs wegen Abwesenheit des Pfandschuldners (1. 6 C. 2.51), des Testamentes wegen Inoffiziosität (1. 31 C. 3. 28) und der Dechargierung eines städtischen Verwaltungsbeamten wegen Unrichtigkeit der anerkannten Rechnung (1. 13 \& 1 D. 44.3). 
Während retractare und retractatio in einem anderen Sinne als in dem eines auf Rückgängigmachung bereits eingetretener Rechtswirkungen gerichteten Angriffs überhaupt nicht vorkommt ${ }^{1}$ ), finden sich zwei andere technische Ausdrücke sowohl in dieser als in anderer Bedeutung. Das sind rescindere ${ }^{2}$ ) (rescissio) und revocare (revocatio).

I. Rescindere.

1. Vereinzelt begegnen wir dem Worte als dem Ausdrucke für die Aufhebung von Vertragswirkungen durch contrarius consensus in

1. 96 § 1 D. 46.3 Papin. 1. 11 resp. Eine Mündel als Erbin eines Magistrats, der aus datio tutoris für einen $\mathrm{Pu}$ pillen diesem auf Ersatz haftete, wurde von dieser Haftung durch einen Vergleich liberiert, welchen ihre Tutoren mit dem inzwischen mündig gewordenen Gegner abschlossen. Zur Erfüllung dieses Vergleichs hatten die Tutoren dem Gegner eine Abfindung gezahlt. Die Mündel wollte den Vergleich nicht ratihabieren. Das soll dessen Wirksamkeit zwischen ihr und ihrem Gegner nicht berühren; sie kann sich höchstens an ihre Tutoren halten. Wenn jedoch der Gegner, mit Aufhebung des Vergleichs und seiner Folgen einverstanden, den Tutoren die Abfindungssumme restituiert, so tritt auch der Vergleich außer Wirksamkeit und die Haftung der Mündel als Erbin des Magistrats besteht von neuem. Diese Aufhebung des Vergleichs wird ausgedrückt durch: 'rescisso quod gestum est'.

2. Häufiger findet sich rescindere im Sinne von „obrigkeitliche Verfügungen zurücknehmen ", d. i. erklären, daß man eine eigene Verfügung als nicht geschehen behandelt sehen wollte.

So in 1.42 D. 42.1 Paul. 1. 3 responsor. . . rescindere quidem sententiam suam ... praetorem non posse;

1. 27 p. D. 48. 19. Callistrat. 1. 6 cognit.: non solere praesides... quae pronuntiaverunt, ipsos rescindere ...

Rubr. Cod. 7. 50. Vergl. mit 1.1 und $2 \S 1$ eod.: Neque suam, neque decessoris sui sententiam quemquam posse revocare in dubium non venit.... Gordian.

1) Über $1.7 \$ 6$ D. 24.1 s. unten S. 119. - ${ }^{2}$ ) cf. Endemann, Verbotsgesetze S. 15 Note 2. 
Quod si aliter actum fuerit, in integrum restitutio permittitur. nam iudicatum contra maiores annis 25 non oppositae praescriptionis velamento citra remedium appellationis rescindi non potest. - Diocl. et Maxim. a. 294.

Vermutlich gehört hierher auch 1.5 D. 50. 9. Callistratus 1. 2 de cognit.: Quod semel ordo decrevit, non oportere id rescindi ...

3. Sehr häufig ${ }^{1}$ ) wird von rescindere (rescissio) gesprochen, um die völlige Wirkungsunfähigkeit eines Tatbestandes zu kennzeichnen, sei es daß rescindi von der zu erwartenden Wirkung des Tatbestandes oder von dem Tatbestande selber ausgesagt wird.

Von der zu erwartenden Wirkung des Tatbestandes geschieht es in:

l. $5 \S 2$ D. 40.9. Iulian 1. 64 digest.: Si ... Stichum manumiserit: libertas per legem Aeliam Sentiam rescinditur.

1. 15 D. 42.8. Idem 1.49 digest. ... quia, libertates ut rescindantur, utrumque in eorundem persona exigimus et consilium (scil. fraudandi) et eventum ....

1. 2 C. 11.63 (62): Libertates, quas mancipiis ex fundis patrimonialibus atque emphyteuticis qui fundorum non sunt domini praestiterunt, rationales huiusmodi praecepti auctoritate rescindant.

l. 5 p. D. 48.6. Marcian lib. 14 institut.: Obligationem vi extortam lex rescindit.

Von dem Tatbestande selber in:

1. 7 \$ 16 D. 2. 14. Ulp. 1.4 ad edict.: Stipulatio .... de his pro quibus pacisci non licet, servanda non est, sed omnimodo rescindenda.

1. $64 \S$ T D. 35. 1. Terentius Clemens 1.5 ad leg. Iul. et Pap. Papp. . . . ipso iure rescindi quod fraudandae legis causa esset adscriptum (scil. condicio, si non nupserit).

1. 17 D. 39. 6. Iulian. 1.47 digest.: . . . possunt videri etiam donationes mortis causa factae rescindi debere, quia legatorum instar optinent. Rubr. Dig. 49.8. Quae sententiae sine appellatione rescindantur.

1) Endemann a. a. O. sagt freilich, daß diese Bedeutung von rescindere nur "vereinzelt." vorkomme. 
1. 4 p. und $\S 1$ D. 50. 9. Ulp. 1. singul. de officio curatoris: Ambitiosa decreta decurionum rescindi debent.... Proinde...nihil valebit huiusmodi decretum.

1. 9 C. 5. $71 \ldots$ venditio tamen contra divi Severi orationem facta praesidis sententia non immerito rescissa est. Diocl. et Maxim. a. 285.

1. 1 \& 2 C. $8.23(24) \ldots$ non posse venditionem post soluta pecunia rescindi ... Gordian a. 238.

1. 13 \& 1 C. 9.51. Ita tamen, ut gesta per filium ... rata sint eodem in potestate patria redeunte, ne eorum rescissio efficiat, quod est maxime absurdum, eodem tempore nec in patris nec in sua quemquam fuisse potestate. Constantin a. 321 .

In 1.9 C. 5.71 und in $1.1 \S 2$ C. 8.23 , sowie in der oben angeführten I. 2 C. 11.63 (62) erscheint als Subjekt des rescindere allerdings ein bestimmtes Individuum. Allein es ist doch aus dem Inhalte der Stellen klar, daß die Tatbestände, welche grammatikalisch das Objekt des rescindere bilden, wegen eines rechtlichen Mangels wirkungsunfähig sind, bezw. daß die libertates in 1.2 C. cit. als nicht eingetreten gedacht werden. Man wird daher hier rescindere als Geltendmachung ${ }^{1}$ ) bezw. in 1.9 C.5.71 als richterliche Feststellung der Wirkungslosigkeit zu verstehen haben. $\mathrm{Ob}$ das Gleiche von rescindere in 1.5 C. 8.55 (56) zu gelten habe, läßt sich allerdings nicht mit Sicherheit entscheiden. Das Reskript Diocletians und Maximians lautet: Si donationem rite fecisti, hanc auctoritate rescripti nostri rescindi non oportet. Damit kann sowohl die richterliche Feststellung der Wirkungsunfähigkeit einer rite vollzogenen Schenkung auf Grund kaiserlichen Reskriptes ausgeschlossen werden sollen, als auch die Möglichkeit eines auf die Beseitigung der Wirkungen gerichteten Angriffs.

Hinwieder glaube ich, als Belege für die Bedeutung von rescindi im Sinne von Verneinung der Wirkungsfähigkeit eines Tatbestandes heranziehen zu müssen alle jene Stellen, welche von rescindi der Testamente bei begründeter querela inofficiosi sprechen, wie

1) Vgl. das nirritam facere venditionem" in $1.77 \$ 5$ D. 31. 
1. 8 \$16 D. 5.2. Ulp. 1.14 ad edict.: Si ex causa inofficiosi .... iudex ... pronuntiaverit contra testamentum nec fuerit provocatum, ipso iure rescissum est.

1. 17 pr. D. eod. Paul. l. 2 quaest.: . . . . rescisso testamento ... quasi centumviri ... cum facerent intestatum.

l. 32 C. $3.28 \ldots$ nec occasione minoris quantitatis testamentum rescindatur. Iustinian.

$\S 270$ Vat. fr. . . . has (scil. donationes) rescindi ad instar inofficiosi testamenti sacris constitutionibus parentum nostrorum evidenter continetur. Diocl. Maxim. et Const. et Gal. a. 294.

Hier tritt zwar die Wirkungslosigkeit des Testamentes nicht ein ohne den Parteiangriff der querela inofficiosi; allein dieser Angriff hat nicht den richterlichen Ausspruch zum Ziele, daß dem Testament die Wirksamkeit entzogen werde, sondern die Feststellung, daf es pflichtwidrig sei. ${ }^{1}$ ) An diese Feststellung knüpft sich kraft Gewohnheitsrechtssatzes die Folge der Wirkungslosigkeit; diese Folge heißt rescissum est testamentum, rescinditur testamentum.

Daran kann auch die Ausdrucksweise nichts ändern, der wir in folgenden zwei Kodexkonstitutionen begegnen:

1. 24 C.3.28. Testamentum militis filiifamilias in castrensi peculio factum neque a patre neque a liberis eius per inofficiosi querellam rescindi potest. Diocl. et Maxim. a. 294.

l. 16 C. 3.36. Filii patris testamentum rescindendi, si hoc inofficiosum probare non possunt, nullam habent facultatem .....

Denn so sehr es auch auf den ersten Blick scheinen möchte, daß hier die Rescission des Testaments ein Angriffsakt der Querelberechtigten sei, so unzweifelhaft ist es, daB der Erfolg der Querel die Deklaration der Inoffiziosität allein ist, und daß erst an diese ohne weiteren Angriff sich die Wirkungslosigkeit von Rechts wegen anknüpft. Demnach kann rescindi potest und facultatem rescindendi habent nur bedeuten: die Möglichkeit, durch das Mittel der querella inofficiosi zu bewirken, daß der Tatbestand eintrete, welcher die Wirkungslosigkeit (rescissio) im Gefolge hat.

$\left.{ }^{2}\right)$ Köppen, Lehrbuch des heutigen römischen Erbrechts S. 575 . Zeitschrift für Rechtsgeschichte. XXIV. Rom. Abt. 
4. ${ }^{1)}$ Weitaus am gewöhnlichsten ist der Gebrauch von rescindere in dem Sinne, daß es die Wiederaufhebung einer bereits eingetretenen Rechtswirkung zufolge einer Parteitätigkeit bedeutet. Doch lassen sich innerhalb dieser $\mathrm{Be}$ deutung wieder zwei Gruppen unterscheiden.

1. Die eine umfaßt Anwendungsfälle von rescindere, in welchen lediglich davon die Rede ist, ob nach dem Eintritt eines rechtswirksamen und in keiner Beziehung mangelhaften Tatbestandes ein Beteiligter die Aufhebung der Wirkungen herbeiführen könne, sei es durch seine Willenserklärung allein, sei es durch Erzielung eines die Aufhebung aussprechenden richterlichen Urteils.

Hierher sind folgende Stellen zu beziehen:

Paul. sent. III. 6, 92: Prolatis codicillis vel alio testamento, quibus ... legatum ... rescissum . .

1. $34 \$ 1$ D. 29.1. Papin. 1. 14 quaest.: Militia missus intra annum testamentum facere coepit neque perficere potuit: potest dici solutum ita esse testamentum, quod in militia fecit, si iure militari fuit scriptum; alioquin si valuit iure communi, non esse iure rescissum. \$2. Nec tamen circa militem eadem adhibetur distinctio: nam quocunque modo testamentum fecerit, novissima voluntate rescindetur...

1. 36 D. 40. 7. Papin. 1.2 defin.: In tabulis secundis filio servum data libertate substitutum iure statu liberi prudentes munierunt: quod utilitas recipit, scilicet ut cum sua causa alienaretur, ne patris testamentum filius rescindat.

1. $11 \S 3$ D. 43.24 . Ulp. $1.71^{\prime}$ ad edict.: . . etsi rescissio emptionis in alterius arbitrium conferatur.

Die Rechtswirkung, um deren Aufhebung es sich hier handelt, ist, mit Ausnahme der letzten Stelle, die rechtliche Möglichkeit der Entstehung von Rechten aus letztwilligen Verfügungen; in der letzten Stelle ist es die Wirkung des perfekten Kaufvertrags. Überall wird die "Rescission" in der bloßen Willenserklärung eines Beteiligten erblickt.

An die Aufhebung durch Erzielung einer Sentenz wird man in nachstehenden Fällen zu denken haben:

1) Endemaun a. a. 0. 
1. $7 \S 1$ D. 20.5. Marcian 1. singul. ad formulam hypothecariam: Illud inspiciendum est, an liceat debitori, si hypotheca venierit, pecunia soluta eam reciperare. et si quidem ita venierit, ut, si intra certum tempus a debitore pecunia soluta fuerit, emtio rescindatur, intra illud tempus pecunia soluta recipit hypothecam. si vero tempus praeteriit aut si non eo pacto res venierit, non potest rescindi venditio. $\left.{ }^{1}\right)$

§ 275 Vat. fr. Perfectam donationem mutata voluntate donatoris, etsi parum gratus existet, cui dono res data est, minime rescindi posse saepe rescriptum est.

$\S 314$ eod. ... nec idcirco patris indignatione posse donationem iustam unquam rescindi summa cum ratione placuit.

1. 3 C. 4. 38. ... sicut donatio perfecta facile rescindi non potest, ita legi, quam tuis rebus donans dixisti, parere convenit. Diocl. et Maxim.

1. 13 C. 4. 44. Si maior annis 25 fundum distraxisti, propter hoc solum, quod ementi, ne compararet, socer tuus denuntiavit, emptionem a te rescindi bona fides non patitur. Diocl. et Maxim.

1. 7 eod. ... nam si oblato pretio rescindere venditionem facile permittatur. ... Diocl. et Maxim.

1. 23 C. 7. 16. Si tibi testamento directa libertas a domino relicta est, et ex eo successerunt scriptae filiae, non idcirco quod secundum eius voluntatem vel contra de filiis uni praestas obsequium, ceterae filiae tuam rescindere possunt libertatem. Diocl. et Maxim.

1. 30 C. eod. Solo obsequii non praestiti velamento data libertas rescindi non potest. Diocl. et Maxim.

1. 33 C. eod. Licet accepta pecunia dominus manumiserit, tamen tributa libertas rescindi non potuit. ${ }^{2}$ ) Diocl. et Maxim.

1. 18 C. 8. 50. Ab hostibus captis ac postliminio reversis pro huiusmodi casu amissa, ... quae ... per usucapionem

1) Vgl. noch 78 \$ 1 D. 31. - 2) Der Sinn dieses Reskripts ist freilich insofern unklar, als nicht erhellt, weshalb eine manumissio accepta pecunia eher sollte rescindiert werden können als eine manumissio gratuita. 
vel liberationem ex bonis subtracta vel non utendo finita esse videntur, intra annum utilem experientibus actione rescissoria restituuntur. Diocl. et Max.

1. 5 C. 8.55 (56). Si donationem rite fecisti, hanc auctoritate rescripti nostri rescindi non oportet. Diocl. et Maxim. a. 293.

l. 3 C. 8. 56. Nec fratris sui mortis causa recte factam donationem sorori rescindere licet. Diocl. et Maxim. a. 293.

1. un C. $8.49(50)$. Filios et filias ceterosque liberos contumaces ... leges emancipatione rescissa damno libertatis immeritae multare voluerunt.

2. Die andere Gruppe zeigt uns rescindere als Folge des wegen rechtlicher Mängel eines Tatbestandes auf denselben unternommenen Parteiangriffs. Dahin gehören:

1. 15 D. 2. 15. Paul. 1. 1 sent.: Pacto convento Aquiliana quidem stipulatio subici solet. sed consultius est, huic poenalem quoque stipulationem subiungere: quia rescisso forte pacto poena ex stipulatu peti potest. Zwar sagt die Stelle selbst nichts darüber, daß rescisso pacto eine Aufhebung des pactum transactionis causa conventum infolge einer rechtlichen Mangelhaftigkeit dieses pactum bedeute; nichtsdestoweniger haben wir mit Sicherheit diese Bedeutung anzunehmen. Denn keine der anderen an sich möglichen Bedeutungen ist zutreffend.

$\mathrm{Da}$ an eine anfängliche Wirkungsunfähigkeit des pactum nicht zu denken ist, ergibt sich ohne weiteres aus dem Umstande, daß die rescissio des pactum nach dem ganzen $\mathrm{Zu}$ sammenhang als etwas der stipulatio Aquiliana Nachfolgendes gedacht wird. Dazu kommt, daß die Frage der Wirksamkeit der stipulatio Aquiliana diesfalls gar nicht aufgeworfen werden könnte im Hinblick auf $1.7 \S 16$ D. $2.14 .^{1}$ )

Ebensowenig ist rescindere als vertragsmäßige Aufhebung des pactum denkbar. Denn eine solche wäre nicht imstande, der stipulatio Aquiliana die Kraft zu nehmen.

So bleibt nur übrig, daß der Verfasser der Stelle den Fall im Auge hatte, es sei infolge Klage des Promittenten die Wirksamkeit des pactum aufgehoben worden. Denn

1) Glück Bd. IV S. 549 Note 45. 
alsdann stand fest, daß die Fassung der stipulatio Aquiliana: quidquid te mihi ex quacunque causa dare facere oportet oportebit für die causa transactionis nicht zutraf.

Eine derartige Entkräftung der transactio konnte aber nur erfolgen, wenn der Tatbestand der transactio nicht in Ordnung war.

I. $9 \S 4$ D. 4. 2. Ulp. 1. 11 ad edict.: Volenti autem datur et in rem actio et in personam rescissa acceptilatione vel alia liberatione. Hier besteht die Mangelhaftigkeit des Tatbestandes in dem unterlaufenen Zwange.

1. 24 \& 1 D. 4. 4. Paul. 1.7 sent.: Non semper autem ea quae cum minoribus geruntur, rescindenda sunt. Wo der Regel nach die Rescission stattfindet, da ist es die minor aetas des Handelnden, welche die Rescission rechtfertigt.

I. 18 D. 11. 1. Iulian 1. 4 ad Urseium: Qui ex dimidia parte heres erat, cum absentem coheredem suum defendere vellet, ut satis dationis onus evitare possit, respondit, se solum heredem esse et condemnatus est; quaerebat actor, cum ipse solvendo non esset, an rescisso superiore iudicio in eum qui re vera heres erat, actio dari deberet. Proculus respondit, rescisso iudicio posse agi, idque est verum.

Der Fehler, an welchem das iudicium leidet, ist jedenfalls eine der causae restitutionis, welche ist nicht gesagt; vermutlich aber ist der dem Kläger gegenüber gespielte dolus gemeint. ${ }^{1}$ )

1. $47 \S 3$ D. 15. 1. Paul. 1. 60 ad edict.: $\mathrm{Si}$ creditor servi ab emptore esset partem consecutus, competere in reliquum in venditorem utile iudicium Proculus ait, sed re integra non esse permittendum actori dividere actiones ... satis enim esse hoc solum ei tribui, ut rescisso superiore iudicio in alterum ei detur actio, cum electo reo minus esset consecutus: et hoc iure utimur.

Auch hier handelt es sich um Restitution und zwar gegen die konsumierenden Wirkungen des iudicium. ${ }^{2}$ )

1) Burchardi, Wiedereinsetzung $\$ 20$ S. 380 . Savigny, Syst. III. S 386. $-{ }^{2}$ ) cf. Keller, Litiskontestation $\$ 64$. 
Die Mangelhaftigkeit des iudicium, welche zur causa restitutionis erhoben wurde, bestand in der Unmöglichkeit desselben, das ganze peculium servi zu erfassen. ${ }^{1}$ )

1. 23 D. 19. 2. Hermog. 1.2 iuris epitom.: et ideo praetextu minoris pensionis, locatione facta, si nullus dolus adversarii probari possit, rescindi locatio non potest.

Der Mangel des Tatbestandes, wegen dessen reszindiert werden könnte, besteht hier wieder im dolus des Gegners.

1. $1 \S 12$ D. 38.5. Ulp. I. 44 ad edict.: ... neque omnino rescindere debemus venditionem. . . Die Reszission, von der hier gesprochen wird (mittels actio Faviana) setzt dolus des Verkäufers voraus. Das Gleiche trifft zu in

1. 22 D. 42.8. ... nisi id in fraudem creditorum factum sit et ea via iuris occurratur, qua creditorum fraudes rescindi solent.

l. 11 C. 2. 4. De fideicommisso a patre inter te et fratres vicissim dato, si alter vestrum sine liberis excesserit vita, interposita transactio rata est, cum fratrum concordia remoto captandae mortis alterius voto improbabili retinetur. et non potest eo casu rescindi, tamquam circumventus sis .... nec ..... in integrum restitutionis auxilium impetrare deberes. Valerian et Gallien. a. 255.

Daß hier die restitutio in integrum in Frage steht und daß mithin die Mangelhaftigkeit des Tatbestandes der transactio in der minor aetas liegen würde, wenn i. i. restitutio stattfände, sagt die Stelle mit aller Deutlichkeit. Wenn sie die Restitution verweigert, so geschieht es, weil in dem Vergleich unter den gegebenen Umständen eine laesio (tamquam circumventus sis) nicht erblickt wird.

1. 19. 1. 22. 1. 29 eod.; I. 5 C. 4.44 von Diocl. und Maxim. handeln von rescissio per in integrum restitutionem auf Grund eines wegen dolus mangelhaften Vergleichs; 1. 35 eod. gleichfalls von Diocl. und Maxim. von rescissio wegen metus.

1. 39 C. eod. von denselben Kaisern lehnt die rescissio des Vergleichs mit der Motivierung ab, daß die Ansicht falsch sei, wonach ein Vergleich rechtsbeständig erst nach Ablauf einer bestimmten Zeit werde, oder anders ausgedrückt,

1) Vgl. Keller a. a. O. S. 545 Nr. 1. 
daB der Nichtablauf einer bestimmten Frist einen Mangel des Tatbestandes transactio ausmache.

In 1.10 C. 2.12 von Antoninus wird die rescissio rei iudicatae verweigert, weil die dolose Vertretung des dominus durch den Bevollmächtigten kein Mangel des iudicium gegenüber dem Prozeßgegner sei.

In 1.17 C. 4.32 von Philippus. Si ea lege possessionem mater tua apud creditorem tuum obligavit, ut fructus in vicem usurarum consequeretur, obtentu maioris percepti emolumenti propter incertum fructuum eventum rescindi placita non possunt erkennt wegen der incertitudo fructuum das maius emolumentum nicht als einen Tatbestandsfehler des pactum antichreticum an.

In $1.15 \S 1^{\text {a }}$ C. 7.2 spricht Justinian unter Bezugnahme auf eine constitutio divi Marci davon, daf die Zulassung der addictio bonorum libertatum servandarum causa intra annum post venditionem bonorum für die Käufer nichts Neues bedeute, da sie sich ja oft die rescissio intra annum gefallen lassen mußten. Hiermit spielt Justinian auf die in integrum restitutio intra annum des klassischen Rechts an, mithin auf Fälle, in welchen die emtio an einem Mangel litt, der die restitutio begründete.

l. 11 C. 7.43 und $1.2 \S 1$ C. 7.50. Valerian et Gallien. bezw. Diocl. et Maxim. nennen die Aufhebung eines Judikats durch Appellation ein rescindi des Judikats. Die Mangelhaftigkeit besteht hier in der noch laufenden Appellationsfrist.

Überblicken wir die Reihe von Quellenaussprüchen über die Rescission von Rechtswirkungen aus mangelhaften Tatbeständen, so zeigt sich, daB es sich hier überall um eine subjektive Befugnis eines Beteiligten handelt, die Aufhebung der bereits eingetretenen Wirkungen zu verlangen. Ohne dieses Verlangen, mithin ohne einen auf die eingetretenen Wirkungen gerichteten Angriff würden sie fortbestehen. Im Gegensatze hierzu lassen jene Stellen, wo von rescissio eines wegen rechtlicher Mängel wirkungslosen oder wirkungslos gewordenen Tatbestandes die Rede ist, darüber keinen Moment einen $\mathbf{Z}$ weifel, daß die Wirkungslosigkeit durch einen Parteiangriff nicht bedingt ist. 
Wir finden also für rescindere, wo es von mangelhaften Tatbeständen ausgesagt wird, einen ganz scharf unterschiedenen Bedeutungsdualismus: man könnte von rescissio per hominem einerseits und von rescissio ipso iure oder per legem anderseits sprechen. ${ }^{1}$ )

Ein ganz ähnlicher Dualismus läßt sich

II. für revocare aufzeigen.

Wir begegnen einer revocatio per legem in folgenden Stellen:

1. 1 C. 7. 11. Certum est non alias directas libertates per legem Aeliam Sentiam revocari, nisi ..... Alexander a. 223.

Daß hier revocari nicht auf eine durch Angriff gegen den Freilassungsakt bewirkte nachträgliche Umstoßung desselben bezw. seiner Wirkungen hindeutet, folgt aus: 1. $27 \mathrm{p}$. D. 40.9 'liberque esse prohibetur' und 1. 24 D. eod.: 'impediri libertatem'.

I. $16 \S 3$ D. 40.9. Paul. 1.3 ad leg. Aeliam Sentiam: Aristo respondit a debitore fisci qui solvendo non erat manumissum ita revocari in servitutem debere, si non diu in libertate fuisset, id est non minus decennio: plane ea quae in fraudem fisci in sinus eius collata sunt, revocanda.

Zum Verständnis dieses Responsum muß man sich vergegenwärtigen, daß dem römischen Rechte die Aufhebung der einmal verliehenen Freiheit prinzipiell widerstrebte ${ }^{2}$ ) und nur für den einen Fall der ingratitudo liberti aus den Quellen nachweisbar ist. Deshalb wird von vornherein im Zweifel zu vermuten sein, daß die "Revokation" des Freigelassenen in servitutem in unserer Stelle nicht gleichbedeutend ist mit Aufhebung der Freiheit. Diese Vermutung wird zur Gewißheit, wenn man erwägt, daß die Stelle von einem diu in libertate esse des Freigelassenen spricht, d. h. dem blof faktischen Zustande der Freiheit. Wäre die manumissio wirksam gewesen, so könnte nicht von einem bloß faktischen Zustande der Freiheit die Rede sein. In

1) Die Definition 'lex rescindit' umfaßt also nicht sowohl Anfechtbarkeit wie Nichtigkeit. Contra Endemann a.a. O. S. 16 oben. $\left.-{ }^{2}\right)$ ef. $1.9 \$ 6 ; 1.10$ D. $4.4 ; 1.24$ D. $4.3 ; 1.9 \$ 2$ D. $4.2 \S 5$ J. 3.11. Hierzu Windscheid, Pand. $\$ 80$ Anm. 2. 
servitutem revocari debere ist daher zu verstehen als die richterliche Konstatierung der Unwirksamkeit des Freilassungsaktes. Dieselbe ist erst durch zehnjähriges in libertate esse ausgeschlossen, d. h. der zehnjährige Freiheitsbesitz ist selbständiger Erwerbsgrund der bis dahin nicht vorhandenen Freiheit. Aber auch in dem Schlußsatz der Stelle bedeutet 'revocanda' nichts anderes als den richterlichen Ausspruch der Unwirksamkeit der in sinus eius collata. Denn diese revocatio soll ja trotz des zehnjährigen Freiheitsbesitzes noch zulässig sein. Das erklärt sich wohl, wenn man von der Voraussetzung ausgeht, daß während des zehnjährigen Zeitraums der Freigelassene noch Sklave war und als solcher nichts erwerben konnte, während die Beziehung des Wortes auf die Paulianische Klage in Widerspruch geriete mit der einjährigen Verjährungsfrist dieses Rechtsmittels.

1. 30 D. 49. 14. Marcian 1. 3 instit.: Ne procuratores Caesaris bonorum actores, quae ad fiscum devoluta sunt, alienent imperatores Severus et Antoninus imperatores rescripserunt: et si manumissi fuerint revocantur ad servitutem.

Zunächst spricht auch hier die Vermutung dagegen, daß eine Aufhebung der Freiheit mit revocantur gemeint sei; dazu kommt die Zusammenstellung der gesetzwidrigen oder doch vollmachtswidrigen manumissio mit der gleichbeschaffenen alienatio. Die letztere war von vornherein wirkungslos ${ }^{1}$ ), weshalb sollte es die manumissio nicht gewesen sein? Wir sind daher genötigt, in revocantur die richterliche Konstatierung der Wirkungslosigkeit der Freilassung zu erblicken.

1. 6 \$ C.6.50. Alexander a. 223. Omnia autem legata .... ad contributionem dodrantis pro rata suae cuiusque quantitatis revocantur. Daß hiermit ein revocari per legem Falcidiam gemeint sei, kann keinem Zweifel unterliegen; denn es steht ja anderweitig fest, daß die Legate, soweit sie contra legem Falcidiam den Erben belasten, von Anfang an der Wirksamkeit entbehren. ${ }^{2}$ )

1) ef. $1.46 \S 7$ D. 49.14. s. o. Bd. XXIII S. 406 Nr. 4. $-{ }^{2}$ ) Windscheid, Pand. $\$ 650$ Note 6; Brinz-Lotmar Bd. IV S. 420 Note 63 . 
1. 9 p. C. 5.9. Iustinian a. 529: .. quae ... mulier quidem secundo marito, vir autem uxori secundae dotis ... nomine vel alio quocumque modo dederit vel reliquerit ampliora his, quae uni filio vel filiae ex anteriore matrimonio progenitis danda vel relinquenda sunt, revocata ad solos filios ex priore matrimonio natos pervenire .... hoc quoque corrigentes omnia quae memorato modo revocantur ... etiam ad eos qui ex secundis nuptiis nati fuerint pertinere .... Vergleicht man hiermit Novelle 22 cap. 27, durch welche Justinian seine in 1.9 cit. vorgenommene Korrektur wieder aufhob, so ergibt sich deutlich, daß revocari im Sinne von Unwirksamkeitserklärung durch das Gesetz gebraucht wird. Denn dort wird von den über das gesetzliche Maß hinausgehenden Zuwendungen an den zweiten Gatten gesagt: quasi neque scriptum neque relictum neque datum aut donatum sit, liberis competat. Übrigens würde schon 1.9 p. cit. selbst genügen, um diese Bedeutung von revocari zu zeigen. Denn als Voraussetzung des revocari wird nicht erwähnt, daß die liberi die Verfügung des verstorbenen parens binubus angreifen müften, sondern es wird direkt bestimmt, daß diese Zuwendungen als revocata an die Kinder gelangen, ihnen gehören.

l. $16 \S 1$ D. 37. 14. Ulpian 1.10 ad leg. Iul. et Pap. $\mathrm{Si}$ quis plures res simul alienando minorem se centenario fecerit, quarum una revocata vel omnium partibus maior centenario efficitur; utrum revocamus omnes an pro rata ex singulis, ut centenarium eum faciamus? magisque est, ut omnium rerum alienatio facta nullius momenti sit.

Schon der Gebrauch des Plural in der Frage des Juristen 'an' revocamus?' zeigt, daß hier nicht auf eine Umstoßungshandlung des Patrons hingewiesen wird. Jeder Zweifel an der Bedeutung von revocare schwindet aber angesichts der das revocari bejahenden Antwort, indem hier revocari mit nullius momenti esse vertauscht wird.

I. $16 \S 2$ eod. . ... ipso iure non revocabitur ...

1. $32 \S 7$ D. 24.1. Ulpian 1.33 ad Sabin. Si maritus uxori donaverit et mortem sibi ob sceleris conscientiam consciverit vel etiam post mortem memoria eius damnata sit, 
revocabitur ${ }^{1}$ ) donatio: quamvis ea quae aliis donaverat valeant, si non mortis causa donavit. Die Schenkung unter Ehegatten hat nur insofern eine Rechtswirkung, als sie in Ermangelung des Widerrufs konvalesziert, falls der Schenker den Beschenkten nicht überlebt. Aber auch diese Wirkung erlischt kraft Rechtens in dem besonderen Falle der Stelle. Das bedeutet revocabitur. Denn es ist klar, daß Subjekt des revocare in diesem Fall der bereits verstorbene Schenker nicht sein kann. Überdies wird diese Bedeutung von revocari noch deutlich ins Licht gestellt durch den Gegensatz 'quamvis ... valeant', welcher zeigt, daß revocabitur als synonym gedacht wird mit non valebit, wie umgekehrt non revocanda in $1.32 \S 24$ eod. mit valere gleichbedeutend gebraucht wird.

1. 57 \& 2 C. 1.3 (lex restituta). Das hier dem lateini-

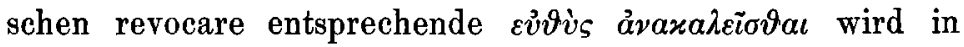
seiner Bedeutung klar durch die Umgebung, in der es sich findet; die in dem Gesetze verbotenen Geschäfte des Ökonomus etc. über das einer pia causa Hinterlassene werden nämlich für wirkungslos erklärt mit den Worten: äxo@ov

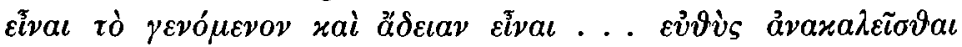

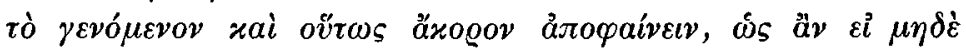

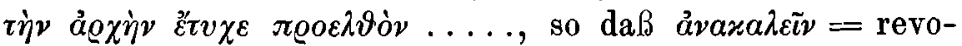
care nur die Geltendmachung der Unwirksamkeit, nicht die Umstoßung der Wirksamkeit bedeuten kann.

1. $2 \S 1$ C. 4. 46. Diocl. et Maximian. Sin autem venditio nulla iusta auctoritate praesidis praecedente facta est, hanc ratam haberi iura non concedunt, idque quod frustra gestum est revocari oportet. .... Das Reskript handelt von dem $Z$ wangsverkauf eines praedium desertum wegen Steuerrückständen. Dieser setzt nach 1. 2 pr. eod. permissum praesidis voraus; mangelt solche permissus, so kann der Verkauf nicht als wirksam betrachtet werden: ratam haberi iura non concedunt; er ist frustra gestum. Seine revocatio kann sohin nur sein die richterliche Feststellung seiner Unwirksamkeit.

1) Synonym wird retrahere in 1.6 C. $5.3 ; 1.1$ p. C. 5.27 und 1.2 C. 5.74 gebraucht. 
l. 98 \& 1 D. 46.3. Paulus 1.15 quaest.: Diversum respondetur in ea pecunia sive re, quam patronus post mortem liberti per Fabianam aufert: haec enim actio cum sit nova, partam liberationem non potest revocare. Im principium der Stelle wird bemerkt, daß die solutio eines geschuldeten statuliber oder einer res sub condicione legata nur ex eventu liberieren könne 'scilicet quo casu certum erit remanere eas’. Im Gegensatze hierzu liberiert nach $\$ 1$ die solutio einer res, welche der Patron des Schuldners später mittels actio Fabiana dem Empfänger abstreitet, sofort. Die liberatio ist ius quaesitum für den Leistenden. Abgelehnt wird demnach die Wiederaufhebung der liberatio, aber nicht als Folge eines vom Empfänger gegen den Leistenden gerichteten Angriffs, sondern als gesetzliche Wirkung der Entziehung, welche der Empfänger seitens des Patrons erleidet. Revocari drückt sohin in der Stelle die ohne Zutun der Beteiligten an einen Tatbestand geknüpfte Aufhebung einer Rechtswirkung aus.

1. 3 C. 5. 29. Alexander a. 228. Si ut proponis, pupillo cuius meministi pater inutiliter testamento tutores dedit et, priusquam ii confirmarentur, alii ab eo cuius interest dati sunt, id quidem, quod iure gestum est, revocari non potest. ....

Daß revocari non potest den Gedanken ausdrückt: die datio tutoris könne nicht für ungültig erklärt werden (nämlich durch den iudex, von dem noch am Schlusse der Stelle die Rede ist), folgt ohne weiteres aus der Erwägung, daß ein Grund für die Aufhebung der tutela dativa ohnehin nicht denkbar wäre. Die Frage konnte nur sein, ob nicht eine nachträgliche confirmatio der tutores testamento dati, die Unwirksamkeit der inzwischen erfolgten obrigkeitlichen datio bedinge. Die Antwort geht dahin, daß die nachträgliche Konfirmation nicht erfolgen dürfe, vermutlich um jene Konsequenz mit Sicherheit auszuschließen.

l. 6 C. 8. 55 (56). Diocletian et Maximian a. 294. Velles nec ne filio tuo praedia itemque mancipia donare, fuit initio tibi liberum. desine itaque postulare, ut donatio quam perfeceras revocetur sub praetextu mariti ac liberorum absentiae, cum huius firmitas ipsorum praesentia non indigeret. 
Hier ging also die postulatio der Schenkerin darauf, ut donatio revocetur; sie wurde mit der Behauptung begründet, daß die donatio zur Wirksamkeit der praesentia mariti et liberorum bedürfe. Sonach $\mathrm{mu} \beta$ die postulatio, ut revocetur den Antrag auf richterliche Feststellung der Unwirksamkeit bedeuten. Man vergleiche noch:

1. 2 \& 1 D. 50. 8. Ulp. 1.3 opinionum: ... et ideo . . quae decurionibus conducere non licet, secundum legem usurpata revocentur. Vat. fr. 270.

Eine besondere Spielart der Bedeutung von revocare in dem hier betrachteten Wortsinne ist die Erklärung des Schenkers, daß es bei der Wirkungslosigkeit der Schenkung bewenden solle. Belege hierfür bieten:

1. 21 pr. i. f. D. 24.1 Ulp. 1.32 ad Sabin.: . . . non enim donat, qui necessariis oneribus succurrit. ergo et si consensu mariti profecta est mulier propter suas necessarias causas et aliquid maritus expensarum nomine ei praestiterit, hoc revocandum non est.

Der sogenannte Schenkungswiderruf bei Schenkungen unter Ehegatten ist nämlich nichts anderes als die Geltendmachung der Wirkungslosigkeit der Schenkung gegenüber dem Beschenkten. Eine den Schenkenden irgendwie bindende Wirkung hat die Schenkung unter Ehegatten bekanntermaßen nicht, solange er lebt. Erst wenn er bis zu seinem Tode die Unwirksamkeit der Schenkung nicht geltend gemacht und den Beschenkten nicht überlebt hat, tritt eine Wirkung der Schenkung für seinen Nachlaß ein. Diese Wirkung kann er nicht zurücknehmen, solange sie noch nicht eingetreten ist. Er kann nur ihren Eintritt verhindern durch die an den Beschenkten gerichtete Erklärung, daß er sie nicht eintreten lassen wolle $d$. $h$. daß es bei der Unwirksamkeit der Schenkung verbleiben soll. Das allein ist der Sinn von revocare donationem inter virum et uxorem. Man kann das der Kürze halber "Zurücknahme" der Schenkung nennen, obwohl z. B. 1.32 \& D. 24.1 zeigt, daß auch dem heres des Schenkers revocandi potestas erteilt wird, wenn nur der Schenker bereits revoziert hatte. Es ist doch klar, erstens, daß der Widerruf oder die Zurücknahme im eigentlichen Wortverstande seitens des Erben gegenstandslos sein mußte, 
nachdem sie durch den Erblasser bereits erfolgt war, zweitens, daß zurücknehmen nur kann, wer gegeben hat, was der Erbe des Schenkers nicht getan hat. Der juristische Inhalt von 1. $32 \S 4$ cit. ist demnach der, daB die Wirkungslosigkeit der Schenkung unter Ehegatten eine dauernde bleibt, wenn sich der Schenker selbst einmal darauf berufen hat. ${ }^{1}$ )

1. 31 p. D. 39. 5. Papin. 1. 12 respons.: Donationes in concubinam collatas non posse revocari convenit nec si matrimonium postea fuerit inter eosdem contractum ad irritum recidere quod ante iure valuit. Die Stelle ergibt, daß die Schenkung an die Konkubine rechtswirksam ist (iure valuit); revocari non posse bezeichnet den Ausschluß der für die donatio inter virum et uxorem anerkannten revocatio.

1. 2 D. 41. 6. Marcellus 1. 22 digest. Hier stellt Marcellus die Vindikation der geschenkten Sache seitens des Schenkers gegen den Beschenkten als einen Fall der revocatio dar.

l. 18 C. 5. 16 . Diocl. et Maximian a. 293. A marito in uxorem donatione collata matrimonii tempore nec initio dominium transferri potest nec post, si .... ab eo qui donavit fuerit revocata, potest convalescere. Die Eigentumsschenkung an die Frau überträgt Eigentum nicht; für die Zurücknahme einer übereignenden Rechtswirkung ist kein Raum; revocata ist die donatio also, wenn der Schenker sich auf ihre Wirkungslosigkeit berufen hat.

Revocare als Tätigkeit einer Partei, welche die Aufhebung vorhandener Rechtswirkungen verursacht (revocare per hominem) kommt in den Quellen in folgenden Anwendungen vor:

I. Einmal als eine auf die Umstoßung der Wirkungen eigener Handlungen gerichtete Tätigkeit.

1. 5 C. 7. 8. Alexander a. 223...... nam ipse manumissor, si fraudem se fecisse creditoribus, ut revocet libertates, audeat dicere, audiri non debet, nec heredes eius.

1) Vgl. Vat. fr. $\$ 276$. Ähnlich die revocatio des schenkenden paterf. gegenüber dem beschenkten Hauskind Vat. fr. $\$ \S 277.278$. Hierzu Savigny, Syst. IV S. 228 Note 7 und die revocatio ex lege Cincia in Vat. fr. $\$ 313$. 
1. 20 C. 7. 16. Diocl. et Maxim. a. 293: Sicut semel praestitam libertatem revocari non licet ...

1. 3 i. f. C. 6. 36. Diocl. et Maxim. a. 290. . . . id quod priori codicillo inscripserat, per eum in quem postea secreta voluntatis suae contulerat, si a prioris tenore discrepat, ... revocatum esse.

Die nach der letzten Stelle aufgehobene Rechtswirkung bestand freilich nur in der Möglichkeit eines Rechtserwerbs für den Fall des Todes des Testators.

1. 4 C. 8. 55. Diocl. et Maxim. a. 293. Confiteri in fraudem te alterius donasse professionem inhonestam continere intellegas. itaque si donationem perfecisti, eam revocare non potes ex memorata adlegatione sub obtentu paenitentiae. Hier weist revocare auf den Versuch des Schenkers hin, die Wirkungen einer Schenkung inter vivos wieder aufzuheben. ef. 1.4 C. 7.75.

Desgleichen in Vat. fr. §§ 262. 287. 312.

1. 1 C. 4. 46. Antoninus: Venditionem ob tributorum cessationem factam revocari non oportet neque priore domino pretium offerente neque creditore eius iure hypothecae sive pignoris ..... Revocari venditionem bezeichnet die Aufhebung der Wirkungen des Verkaufs auf Verlangen des früheren Eigentümers (oder seiner Pfandgläubiger).

1. 8 C. 8.27 (28). Gordianus a. 239: Si prius quam distraheretur pignorata possessio, pecuniam creditori obtulisti eoque non accipiente contestatione facta eam deposuisti ... pignoris distractio non valet; quod si prius, quam offerres, legem venditionis exercuit, quod iure subsistit, revocari non debet. Auch hier wäre revocare die Aufhebung des Pfandverkaufs.

l. $10 \S 1$ C. eod. Diocl. et Maxim. a. 290: Sane si debitore distrahente comparaverit, consensu emptionem perfectam .... revocari exemplo grave est. Der Verkauf des Pfandobjekts durch den Pfandschuldner an den Gläubiger ist - im Gegensatze zu dem des Gläubigers an sich selbst - vollwirksam, und dessen Rückgängigmachung kann vom Verkäufer nicht verlangt werden. 
1. 7 C. 5. 16. Antoninus a. 232 : .. sed si matrimonium iure non valuit; licet ipso iure donatio tenuerit, quia tamen indigna persona eius fuit, qui nee maritus potest dici, utiles actiones super revocandis his tibi competunt. Es handelt sich um eine Schenkung der Frau an den in rechtsunwirksamer Ehe mit ihr lebenden Mann. Diese soll rückgängig gemacht werden können mittels actio gegen den Beschenkten.

1. $36 \S 2$ D. 29.1. Papinian 1. 6 resp.: Miles in supremis ordinandis ignarus uxorem esse praegnatem ventris non habuit mentionem. post mortem patris filia nata ruptum esse testamentum apparuit neque legata deberi, si qua vero medio tempore scriptus heres legata solvisset utilibus actionibus filiae datis ob improvisum casum esse revocanda.. Die zugelassenen actiones ad revocandas solutiones sind sichtlich condictiones indebiti als cessae actiones.

1. 1 p.; 1.7 p. $\S \S 1$ u. 2 ; 1.9 C. 8.55 (56). Philippus a. 249; Constantius et Constans a. 349 u. Theodos. et Valent. a. 426. In diesen Stellen wird dem Schenker das ius revocandi wegen Undankbarkeit des Beschenkten bestätigt. Aus $1.1 \S 3$ cit. und $1.7 \S 3$ cit. ist zugleich ersichtlich, daß die Ausübung dieses Rechtes in Erhebung einer Personalklage gegen den Beschenkten besteht auf Rückerstattung des Geschenkten.

l. 59 D. 26. 7. Scaevola 1. 26 digest: Cum hereditas patris aere alieno gravaretur et res in eo statu videretur, ut pupilla ab hereditate paterna abstineretur, unus ex tutoribus cum plerisque creditoribus ita decidit, ut certa portione crediti contenti essent acciperentque; idem curatores iam viri potenti accepti cum plerisque creditoribus deciderunt. an si aliquis tutorum creditor patris pupillae solidam pecuniam expensam sibi ex re pupillae cum usuris fecerit, revocari a curatoribus pupillae ad portiones eas possit, quas ceteri quoque creditores acceperunt? respondi eum tutorem, qui ceteros ad portionem vocaret, eadem parte contentum esse debere.

Da der in Frage stehende tutor die ex re pupillae entnommenen Geldstücke zu seinem Eigentum gemacht hatte, so kann revocari ad portiones nichts anderes besagen, als daß er zur Rückerstattung pro rata gezwungen werden 
könne. Die Klage ist condictio sine causa. Sie fällt unter die hier betrachtete Bedeutung von revocare insofern, als die Mündel so behandelt wird, als habe sie dem tutor solidum gezahlt, sodaß die condictio nun auf die Rückgängigmachung dieser Zahlung gerichtet ist.

Novelle 22 c. 35 Mater tamen donans aliquid filio de suo si ad secundas venerit nuptias, non poterit per occasionem ingratitudinis revocare quod datum est.

II. Sodann findet sich revocare als Ausdruck für den von einem dritten ausgehenden Angriff auf die durch ein frauduloses Geschäft hervorgebrachten Wirkungen zum Zwecke ihrer Beseitigung, wobei dieser Angriff als eine subjektive Befugnis des Angreifers erscheint.

Hierher gehören:

l. 1 \$ 1 D. 42.8. Ulp. I. 66 ad edict.: Necessario praetor hoc edictum proposuit, quo edicto consuluit creditoribus revocando ea, quaecunque in frandem eorum alienata sunt.

1. 6 \&5 D. eod. Idem eod. ... at si in ipsa servi alienatione fraus est, revocabitur...

1. $10 \$ 6$ D. eod. Idem 1.73 ad edict.:... in fraudem creditorum alienatum revocari posse ...

1. 1 C. 7. 75. Antoninus a. 213:... ea quae in fraudem alienata probabuntur revocabis.

1. 4 C. eod. Diocl. et Maxim. a. 293: Filios debitoris ei succedentes velut in creditorum fraudem alienatorum facultatem revocandi non habere notissimi iuris est.

1. 17 p. D. 42. 8. Iulian 1. 49 digest.: Omnes debitores, qui in fraudem creditorum liberantur, per hanc actionem revocantur in pristinam obligationem.

I. $14 \mathrm{D}$. eod. Ulp. 1.6 disput.: Hac in factum actione non solum dominia revocantur.

1. 18 D. eod. Papin. 1. 26 quaest. Etsi pignus.. remiserit .... si in fraudem creditorum fiat, actione utili revocabitur.

1. 24 D. eod. Scaevola 1. singul. quaest. publice tractat: ... an id quod accepit creditor revocandum sit... ut ...revocetur ... revocari nullo modo potest... an ... revocetur... ideoque non revocatur quod percepi. Zeitschrift für Rechtsgeschichte. XXIV. Rom. Abt. 
1. 7 D. eod. Paulus 1.62 ad edict.: Si debitor in fraudem ...vendiderit, deinde hi, quibus de revocando eo actio datur ... petant, ...

l. $6 \$ 10$ D. eod. Ulp. 1. 66 ad edict.: Si quid cum pupillo gestum sit in fraudem creditorum, Labeo ait omnimodo revocandum. ....

l. $10 \$ 1$ D. eod. Idem 1.73 ad edict.: Ita demum revocatur, quod fraudandorum creditorum causa factum est, si eventum fraus habuit .... \$ 11. Si impubes patri heres extiterit eiusque mortui bona veneant, separatione impetrata utriusque fraus erit revocanda...

In all diesen Stellen wird von revocare gesprochen, wo Rückgängigmachung einer alienatio, liberatio, traditio, pignoris remissio, solutio, venditio, eines factum oder gestum in fraudem creditorum, mittels actio Pauliana oder actio in factum in Frage steht.

Die gleiche Bedeutung von revocare findet sich für einen teils gleichen teils ähnlichen Fall in 1.45 pr. D. 49.14 (= Paul. sent. V. 12.1 ${ }^{\text {a }}$ ): In fraudem fisci non solum per donationem, sed quocumque modo alienata revocantur. idemque iuris est, etsi non quaeratur: aeque enim in omnibus fraus punitur ${ }^{1}$ ); ferner in:

Fragm. de iure fisci 20: $\mathrm{Ab}$ eo qui reus criminis postulatus adversam sententiam meruit, tempore reatus quocumque modo alienata a fisco cum quadruplis fructibus revocantur.

1. $11 \$ 1$ D. 48. 20. Marcian 1.... de publ. indiciis: ... in fraudem autem quae alienavit, post condemnationem revocantur.

1. $39 \S 1$ D. 49. 14. Papin. 1. 16 respons.: . . quod participes iudicati solvendo essent revocatis a lienationibus quas fraudulenter fecerant ....

Der Fiskus soll hiernach überall das Recht haben, die geschehene alienatio umzustoßen.

Sehr entschieden kommt revocare in dem besprochenen Sinne zur Geltung in den Fällen der in fraudem patroni

1) Savigny, System IV. S. 29 Note n. 
erfolgten alienatio, vgl.: Paul. sent. III. 3. Ea quae in fraudem patroni a liberto quoquo modo alienata sunt, F'abiana formula tam ab ipso patrono quam a liberis eius revocantur.

Fragm. de formula Fabiana fol. I vers. 6: Et ea quidem quae non mortis causa data sunt, ita revocat, si dolo malo alienata sint. . .

1. 1 \$ 1 D. 38. 5. Ulp. 1.44 ad edict.: Si alienatio dolo malo facta sit.... omni enim modo revocatur cf. $\$ 2$ eod.

l. 16 p. D. 37. 14 . Ulp. l. 10 ad leg. Iul. et Pap.: . . . alienatio quidem vires habebit, verumtamen per Favianam et Calvisianam actionem revocabuntur ea quae per fraudem sunt alienata.... idcirco Faviano vel Calvisiano iudicio revocabitur id quod alienatum est.

Hierzu vergleiche man den Gegensatz ron ipso iure revocari und locum esse Favianae in $1.16 \$ 2$ eod.

III. Ferner wird revocari gleichbedeutend mit in integrum restitui gebraucht.

1. 10 C. 8. 42. Diocl. et Maxim. a. 293: Successores eius qui maior 25 annis in solutum pro debito iure mancipia dedit haec revocare non posse constat.

Hier wird von den Kaisern die den minores und ihren Successoren zustehende in integrum restitutio als revocatio gedacht und solche den Erben eines maior 25 annis verweigert.

1. 2 p. C. 6.35. Severus et Antoninus a. 222: Polla quidem liberam habuit administrandi patrimonii sui potestatem nec idcirco quod pupillus illi heres extitit ea quae ab ipsi finita sunt revocari in disceptationem oportet. Die in integrum restitutio gegen den Vergleich des Grobjährigen steht dem unmündigen Erben desselben nicht zu; revocari in disceptationem wird synonym mit in int. restitui gebraucht.

IV. Endlich kommt revocare vor im Sinne eines prozessualen Angriffs, gerichtet auf Umstoßung eines richterlichen Urteils:

1. 3 C. 2.9 (10) Diocl. et Maxim. a. 294: Sententiis finita negotia rescriptis revocari non oportet... 
1. 3 C. 7. 57. Alexander a. 227: Ea quae causa cognita statuuntur, subscriptionibus revocari non posse saepe rescriptum est.

Paul. sent. V. 33, 1: Ne liberum quis haberet arbitrium retractandae et revocandae sententiae ....

Überblickt man die Anwendungsfälle von revocare, so läßt sich feststellen: Wo revocare die Unwirksamkeit eines Tatbestandes ausdrückt, besteht über diese Bedeutung nach

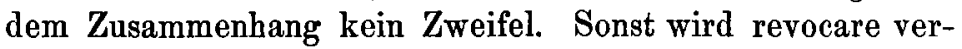
einzelt gebraucht:

a) zur Bezeichnung der Umstoßung letztwilliger Verfügungen seitens des Testators selbst (l. 3 i. f. C.6. 36 S. 111 Z. 3 v. o.);

b) zur Bezeichnung der Umstoßung einer Schenkung wegen Undankbarkeit (l. 1 p.; 1.7 p. $\$ \S 1-2.1 .9$ C. 8.55 S. 112 Z. 16 v. o.);

c) zur Bezeichnung des Rechtsmittels gegen ein Urteil (S. 115 Nr. IV), regelmäßig aber zur Bezeichnung der Umstoßung von Rechtswirkungen, die zufolge eines krankhaften Tatbestandes eingetreten sind, mittels Angriffs auf dieselben:

a) seitens desjenigen selbst, der den Tatbestand gesetzt hat;

$\beta$ ) seitens eines benachteiligten Dritten.

Dies trifft auch für die zahlreichen Fälle zu, wo das Revokationsrecht verneint wird in Ermangelung eines krankhaften Tatbestandes. Wir sind daher berechtigt, dem Ausdruck revocare eine zweite technische Bedeutung zu vindizieren, welche die Gefahr einer Verwechselung ausschließt.

Kommen wir so zu dem Schlusse, daß in unseren Quellen eine technische Bezeichnung für etwas, was nicht Unwirksamkeit eines Tatbestandes, sondern eine zum Angriff auf die erzeugten Wirkungen berechtigende Mangelhaftigkeit ist, in den Wendungen retractare, rescindere, revocare vorkommt, so ist nun der Einwand zu prüfen, „daß die Ausdrücke "rescindere, ... revocare u. a. ebenso häufig von Rechts"geschäften, wie von rechtlichen und tatsächlichen Verhält"nissen gebraucht werden und vielleicht nicht minder oft in 
„Fällen wirklicher Nichtigkeit wie in Fällen von Anfechtbar"keit im Sinne unseres Systems." 1 )

Zunächst kommt es für die Frage des technischen Sprachgebrauchs, welcher bez. der Mangelhaftigkeit eines juristischen Tatbestandes bestehen soll, darauf gar nicht an, ob er ausschließlich für die sogenannten Rechtsgeschäfte besteht oder nicht; ferner ist zu bestreiten, daß die erwähnten Ausdrücke überhaupt zur Bezeichnung von "tatsächlichen" Verhältnissen vorkommen. Die von Schloßmann a. a. O. Anm. 30 hierfür gebrachten Beispiele der Quellen treffen keineswegs zu. Denn libertas in $1.5 \$ 2$ D. 40.9 bedeutet ebenso die „Rechtswirkung des Freilassungsaktes" wie fraudes in 1.22 D. 42.8 die fraudulosen Geschäfte. Endlich ist es allerdings, wie oben ausführlich gezeigt wurde, richtig, daß rescindere und revocare häufig die gänzliche Wirkungslosigkeit (Nichtigkeit) des Tatbestandes ausdrücken; allein, wie ebenfalls dargelegt wurde, so, daß die eine und die andere $\mathrm{Be}$ deutung sich jeweils aus dem Zusammenhange mit Sicherheit ergibt. ${ }^{2}$ )

1) Schloßmann, Zur Lehre vom Zwang S. 23. Auch Schilling, Lehrbuch der Institutionen II $\$ 84 \mathrm{Anm}$. c und Animadversiones criticae ad Ulp. fr. specimen I p. 32 sqq. Endemann, Die civilrechtl. Wirkung der Verbotsgesetze S. 15 N. 1. 2. Schröder, Zur Lehre von den gesetzlichen Veräußerungsverboten S. 106 N. 30. - $\left.{ }^{2}\right)$ Wenn Schil. ling, Lehrbuch a. a. 0 . und Animadv. crit. a. a. 0 . für die Synonymität von nullius momenti esse und rescindi die $1.22 \mathrm{D} .42 .8$ anführt, so beruht dies auf Mißverständnis. Denn in 1.22 wird zwar die Frage aufgeworfen, ob es als factum in fraudem creditorum nullius momenti sei, wenn in vetus creditum unus creditor pignora accepisset. Allein die Antwort ist dahin formuliert: der Gläubiger sei an der persecutio pignorum nicht gehindert, wenn nicht die Verpfändung in frauden creditorum geschehen und die actio angestellt werde, durch welche die fraudulosen Geschäfte umgestoßen zu werden pflegen (rescindi solent). Hier wird also rescindi durchaus nicht gleichbedeutend mit nullius momenti esse gebraucht. Vielmehr wird die Frage, ob nullius momenti implizite verneint und nur die Umstoßung (rescissio) für zulässig erklärt. - Über retractari in $1.7 \$ 6$ D. 24.1 s. oben S. 91 Z. 4 v. u. ff. - Nicht besser steht es mit Schillings Behauptung in Animadv. crit. l. c., daß ipso iure non valere bisweilen im Sinne der Existenz eines Revokationsrechts vorkomme. Der zum Belege angeführte Vergleich zwischen $1.3 \$ 10$ und $1.5 \$ 18$ D. 24.1 beweist nur, daß revocari in letzterer Stelle die Geltendmachung des non valere bedeutet. 
Endemann (Die civilrechtliche Wirkung der Verbotsgesetze S. $15 \mathrm{f}$.) hält für das dem Begriff der lex perfecta Wesentliche nicht die Statuierung der "Nichtigkeit" des verbotswidrigen Handelns, sondern die ${ }_{n}$ Rescission ${ }^{\mu}$ des unerlaubten Geschäftes. ${ }_{n}$ Rescindere geht „aber", so fährt er fort, „nicht in dem anderen technischen Begriffe "nichtig machen" auf. Die römischen Juristen gebrauchen die Ausndrücke: nullum esse, ipso iure non valere, irritum esse, revocari, re"scindi, infirmari und andere derart ohne technische Unterscheidung, „daß nur der eine Schluß dahin möglich ist, daß sie eine den "modernen Begriffen "Nichtigkeit und Anfechtbarkeit" entsprechende „Scheidung nicht kannten. Insbesondere bezüglich des hier interes"sierenden Begriffes 'rescindere' ist festzustellen, daß derselbe ver„einzelt als gleichbedeutend mit absolut wirkungslos gebraucht wird, "nach dem gewöhnlichen, in den Quellen weitaus überwiegenden ,Sprachgebrauch aber die Auflösung eines an sich wirksamen Rechts„geschäfts ausdrückt. Mit anderen Worten also: die als überliefert "anzunehmende Definition 'lex rescindit' umfaßt, um mich der heutigen "Terminologie zu bedienen, sowohl Anfechtbarkeit als Nichtigkeit; ndie Wirkung der lex perfecta nach diesen beiden Richtungen hin ist "in der zur Charakterisierung dieser Gesetzesart benutzten Bezeichnung "zum Ausdruck gebracht."

Diese Ausführung leidet an ungenauer Beobachtung der Quellen in bezug auf rescindi und revocari. Vor allem lassen sich die Beispiele für rescindi als Ausdruck der Unwirksankeit sehr weit über die beiden (a. a. O. Anm. 2) von E. angeführten vermehren (vgl. oben S. 95), sodaß von einem vereinzelten Vorkommen dieser Bedeutung füglich nicht die Rede sein kann. Sodann ist aus den Belegen für die Bedeutung von rescindi als Auflösung eines wirksamen Rechtsgeschäfts die 1.5 p. D. 48.6 auszuweisen; endlich aber zeigen, abgesehen von eben dieser Stelle, die übrigen von $\mathrm{E}$. angeführten Beispiele für die zweite Bedeutung von rescindere, daß es sich dabei - wie auch oben schon gezeigt wurde - um Auflösung von Tatbestandswirkungen infolge eines Angriffs auf dieselben handelt, also um ein rescindere ex voluntate hominis. Dagegen konnte gerade die Wendung lex rescindit oder rescindere in einer Verbindung, welche Rescission kraft der lex selbst anzeigt, nirgends in dem Sinne nachgewiesen werden, daß auch hier ein Angriff erst die Auflösung der Wirkungen herbeiführe, oder laß hier überhaupt erst eine Auflösung solcher in Frage stehe. An einer andern Stelle (S. 32f.) erklärt E., die Begriffe nichtig und anfechtbar seien in den Quellen so wenig nach Inhalt und Terminologie unterschieden, daß dasselbe Geschäft öfter als ipso iure nullum und daun wieder als revokabel bezeichnet werde. Besonders charakteristisch sei hierfür die Vergleichung der $1.3 \$ 10$ und der $1.5 \$ 18$ D. 24.1; während dort Ulpian von der donatio inter v. e. u. sage, ipso iure nihil valet, änßere derselbe Jurist in der letzteren Stelle über den nämlichen Gegenstand: hactenus revocatur donum $a b$ eo eove cui 
donatum est, ut - vindicetur, - condicatur. Nun erhellt aber doch aus dem Zusammenhang letzterer Stelle vollkommen deutlich, daß mit revocatur don um (nicht donatio cf. $1.32 \$ 7$ D. 24.1) gar kein Urteil über die Wirkungsfähigkeit oder -Unfähigkeit der donatio abgegeben wird; dieses Urteil liegt schon in den vorausgehenden Worten: in donationibus autem iure civili impeditis. Revocatur donum zeigt lediglich den Weg an, auf welchem der Schenker das geschenkte Vermögensstück oder dessen Wert wegen Unwirksamkeit der Schenkung wieder in seinen Besitz bringen könne.

Wenn sodann E. a. a. O. für die Unbestimmtheit des Sprachgebrauchs der Quellen sich darauf beruft, daß in den Digesten die Wendungen nullius momenti esse, retractari, irritum esse, infirmari, iure vulgato nulla est, nihil agitur promiscue gebraucht werden,

l. $5 \S 5 ; 7 \S 6 ; 31 \S 4 ; 32 \S 21 ; 52 \S 1$ D. $24.1 ; 43 \S 2$ D. 28.6 , so ist zunächst wegen des in $l .7 \$ 6$ vorkommenden retractari zu entgegnen, daß hier retractari in seiner Grundbedeutung erscheint, in welcher es farblos auf die erneute Erörterung eines Tatbestandes hinweist. Indem der Jurist ausspricht: donationem inter virum et uxorem bona fide gestam non retractari, will er lediglich feststellen, daß eine solche venditio nicht der erneuten Erörterung (nämlich coram iudice) unterliegt. Dabei komnt es ihm auf den Unterschied zwischen Giltigkeit als Gegensatz von Wirkungslosigkeit und zwischen Unanfechtbarkeit nicht an. Wo retractari positiv gebraucht wird, bedeutet es, wie oben gezeigt, die auf Umstoßung vorhandener Wirkung gerichte Tätigkeit allein. Infirmari bezeichnet stets die volle Wirkungslosigkeit eines Tatbestandes ohne Angriff einer Partei (s. oben Bd. XXIII S. 413).

Unrichtig ist es, wenn E. behauptet, in 1. 22 D. 42.8 werde die geschehene Veräußerung als nullius momenti charakterisiert, gleichzeitig aber anerkannt, daß erst noch Rescissionsklage nötig sei. Vielmehr wirft hier Scaevola, wie schon oben bemerkt wurde, znerst die Frage auf, ob die Veräußerung nullius momenti sei. Er verneint sie mit dem Bemerken, daß in dem gesetzten Fall höchstens, nämlich bei fraus in creditores - actio ad rescindendam fraudem stattfinde.

Bedenken könnte eine andere von E. angeführte Stelle erregen: 1. $3 \& 3$ D. 17.2: societas si dolo malo aut fraudandi causa coita sit, ipso iure nullius momenti est, quia fides bona contraria est fraudi et dolo. Obwohl ein erschlichener Kontrakt nur anfechtbar ist, werde die erschlichene societas ipso iure n. m. genannt. Allein ist denn eine societas dolo malo aut fraudandi causa coita ein erschlichener Gesellschaftsvertrag? Kann nicht societas flagitiosae rei gemeint sein? (cf. 1. $35 \$ 2$ D. 18.1; $70 \S 5$ D. 46.1. Vgl, auch die Übersetzung im deutschen corpus iuris.) Dolo malo coita societas wäre dann ein in rechtswidriger Absicht, d. h. zur Ausführung von rechtswidrigen Handlungen eingegangener Gesellschaftsvertrag; societas fraudandi causa coita ein Gesellschaftsvertrag zum Zweck betrügerischer Ausbeutung Dritter. Was aber den 
Übrigens liegt bereits in der Tatsache, daß rescindi und revocari von den Römern in doppeltem Sinne verwendet werden, der Beweis dafür, daß auch ihnen der Gegensatz völlig zum Bewußtsein gekommen war, der unter den zwei Bedeutungen besteht.

Am Ende ist es doch auch sehr natürlich, daß die Sprache zwischen Fällen unterscheidet, wo ein Tatbestandsfehler dem Tatbestand jede Wirkung entzieht, und solchen, wo dieser Fehler den Eintritt der Wirkung nicht ausschlieBt, wohl aber seinerseits bewirkt, daß diese Wirkung in ihrer Fortexistenz von einer ständigen Gefahr bedroht wird. Anderseits ist nicht zu verkennen, daß ein Tatbestand mit solcher, in ihrer Fortexistenz bedrohten Wirkung eine Schwäche in sich trägt, welche dem Tatbestand mit nicht bedrohter Wirkung fehlt. Und deshalb ist nicht abzusehen, weshalb diese eigentümliche Schwäche im Gegensatz einerseits zur vollen Stärke, anderseits zur vollen Wirkungslosigkeit nicht sollte als eine besondere Qualifikation des Tatbestandes aufgefaßt werden können und müssen. Diese Auffassung ist weit entfernt davon, zu leugnen, daß "Tatsachen sich nicht ungeschehen machen lassen" ${ }^{1}$ ), oder „daß das (juristische) Geschäft nicht (mit seinem Abschluß) für immer seine Funktion erfüllt habe" ${ }^{2}$ ), oder zu behaupten, daß das Rechtsgeschäft ein lebendiger Organismus sei, der auch eine krankhafte Konstitution haben könne. ${ }^{3}$ )

$\mathrm{Ob}$ von der Aufstellung des Begriffs der „Anfechtbarkeit" praktische Konsequenzen zu erwarten seien, ist eine Frage für sich, die sich in anderem Zusammenhange wird beantworten lassen. Nur soviel läßt sich schon an dieser Stelle gegen Schloßmann (a. a. O.) „der Satz, daß anfechtbare Geschäfte durch Verzicht auf das Anfechtungsrecht

Sprachgebrauch des Codex für rescindere anlangt, so kann im allgemeinen auf das oben Gesagte verwiesen werden. Hier sei nur bemerkt, daß die von Endemann a. a. 0 . für rescindere im Sinne von "anfechten" citierten 1.8 C. $5.3 ; 1.1$ C. 4.21 und 1.13 C. 5.16 den Ausdruck rescindere überhaupt nicht enthalten.

1) Schloßmann a. a. O. S. 21. - ${ }^{2}$ ) Schloßmann l. c. 3) Schloßmann: 1. c. Gegen Schloßmann: Thon in Jherings Jahrb. 28 S. 41/2. Endemann a. a. O. S. 97. 
oder durch Verjährung des letzteren konvaleszieren können, zeigt sich bei näherer Betrachtung nur als ein anderer Ausdruck des trivialen Satzes, daß ein Rechtszustand solange besteht, als er nicht aufgehoben ist" geltend machen, dah es doch einen Unterschied machen könnte, ob ein normaler Rechtszustand aufgehoben wird, weil eine normale Aufhebungstatsache eintritt oder ob ein abnormaler Zustand beseitigt wird deshalb, weil gegen die Wirkungen aus der Mangelhaftigkeit seines Entstehungstatbestandes reagiert wird, um ein Beispiel zu gebrauchen, ob die Obligation gelöst wird durch Erfüllung oder durch Angriff des benachteiligten Gläubigers, ob das Eigentum aufhört durch freiwillige Tradition bezw. Ersitzung, oder ob durch den richterlichen Spruch auf Anrufen einer Partei. ${ }^{1}$ )

Auch wenn die Art der Beseitigung vorhandener Rechtswirkungen für die einzelnen Fälle der "Anfechtbarkeit" eine verschiedene ist, bleibt dennoch ein systematisches und praktisches Interesse des Begriffs "Anfechtbarkeit" noch immer nach verschiedenen Richtungen möglich, dessen Nachweis weiterer Ausführung vorbehalten bleiben muß.

Nicht minder kann erst an anderer Stelle die Frage untersucht werden, welche Bedeutung der römischen exceptio zukam.

Möge es sich damit wie immer verhalten, an der Tatsache ändert das nichts, daß die Quellen einen Unterschied zwischen vollwirksamen Tatbeständen einerseits, wirkungslosen und mit schwacher, weil existenzbedrohter, Wirkung anderseits in ihrer Sprache zum Ausdrucke gebracht haben.

1) Vgl. Brinz-Lotmar, Pand. (2. A.) Bd. IV S. 421 N. 70. 